\title{
Dopamine Modulation of Transient Potassium Current Evokes Phase Shifts in a Central Pattern Generator Network
}

\author{
Ronald M. Harris-Warrick, ${ }^{1}$ Lisa M. Coniglio, ${ }^{1}$ Nobl Barazangi,, John Guckenheimer, ${ }^{2}$ and Shay Gueron ${ }^{3}$ \\ ${ }^{1}$ Section of Neurobiology and Behavior and ${ }^{2}$ Mathematics Department and Center for Applied Mathematics, Cornell \\ University, Ithaca, New York 14853 and ${ }^{3}$ Department of Mathematics, Technion-I.T.T., Haifa, 32000, Israel
}

Bath application of dopamine modifies the rhythmic motor pattern generated by the 14 neuron pyloric network in the stomatogastric ganglion of the spiny lobster, Panulirus interruptus. Among other effects, dopamine excites many of the pyloric constrictor (PY) neurons to fire at high frequency and phase-advances the timing of their activity in the motor pattern. These responses arise in part from direct actions of dopamine to modulate the intrinsic electrophysiological properties of the PY cells, and can be studied in synaptically isolated neurons. The rate of rebound following a hyperpolarizing prestep and the spike frequency during a subsequent depolarization are both accelerated by dopamine. Based on theoretical simulations, Hartline (1979) suggested that the rate of postinhibitory rebound in stomatogastric neurons could vary with the amount of voltage-sensitive transient potassium current $\left(I_{A}\right)$. Consistent with this prediction, we found that dopamine evokes a net conductance decrease in synaptically isolated PY neurons. In voltage clamp, dopamine reduces $I_{A}$, specifically by reducing the amplitude of the slowly inactivating component of the current and shifting its voltage activation curve in the depolarized direction. 4-Aminopyridine, a selective blocker of $I_{A}$ in stomatogastric neurons, mimics and occludes the effects of dopamine on isolated PY neurons. A conductance-based mathematical model of the PY neuron shows appropriate changes in activity upon quantitative modification of the $I_{A}$ parameters affected by dopamine. These results demonstrate that dopamine excites and phase-advances the PY neurons in the rhythmic pyloric motor pattern at least in part by reducing the transient $K^{+}$current, $I_{\mathrm{A}}$.

IKey words: dopamine, stomatogastric ganglion, postinhibitory rebound, transient $K^{+}$current, $\mathrm{I}_{A}$, neuromodulation, phase shift]

An important goal in neuroethology is to understand the cellular mechanisms by which a single neural network can be modulated to produce a family of related behaviors. Simple rhythmic behaviors are generated by limited neural networks called central

Received Feb. 14, 1994; revised June 20, 1994; accepted June 23, 1994.

This work was supported by NIH NS17323, NSF DMS-9204098, a grant from the Human Frontiers Science Program, and Hatch Act Grant NYC-191410. We thank Bruce Johnson, Jack Peck, Deborah Baro, Bing Zhang, and Robert Levini for useful comments on the manuscript, and Ms. Terri Natoli for assistance in preparation of the manuscript.

Correspondence should be addressed to Dr. Ronald M. Harris-Warrick, Section of Neurobiology and Behavior, Seeley G. Mudd Hall, Cornell University, Ithaca, NY 14853.

Copyright (C) 1995 Society for Neuroscience $0270-6474 / 95 / 150342-17 \$ 05.00 / 0$ pattern generators (CPGs; Selverston and Moulins, 1985; Getting, 1989; Pearson, 1993). The output from a CPG network is not fixed, but can be modified by neuromodulatory and sensory input (Harris-Warrick and Marder, 1991; Harris-Warrick et al., 1992a,c). Nearly every aspect of a rhythmic motor pattern can be changed, including which cells are actively firing and at what intensity, the cycle frequency, and the phasing of cell activity within the cycle. In this article, we address the cellular mechanisms that underlie phase shifts in a simple rhythmic motor pattern. Changes in phasing cause important changes in behavior, for cxamplc, from trotting to cantering or galloping in a quadruped (Grillner, 1981). Phase shifts result from alterations in the relative timing of activity of neurons in the CPG that coordinates the behavior. Much previous work on the cellular mechanisms of phase shifts in behavior has emphasized alterations in synaptic efficacy, demonstrating that changes in the relative amounts of synaptic excitation or inhibition a neuron receives can shift its firing time within the cycle (Cohen and Harris-Warrick, 1984; Eisen and Marder, 1984; Sharp et al., 1992). An alternative mechanism for phase shifts in rhythmic motor patterns can arise from alterations in the intrinsic electrophysiological properties of CPG neurons. Changes in such properties as postinhibitory rebound or plateau potential capabilities can evoke significant changes in phasing of cell activity in a rhythmic motor pattern (Nagy and Dickinson, 1983; Nagy et al., 1988; Elson and Selverston, 1992). In most cases, however, the ionic bases for these modulatory actions are not well understood.

We are studying the pyloric network of the stomatogastric ganglion in the spiny lobster, Panulirus interruptus. This 14 neuron network is one of the best understood CPGs (reviewed in Selverston and Moulins, 1987; Harris-Warrick et al., 1992b): all the component neurons and their synaptic connections are known (Miller, 1987; Johnson and IIooper, 1992). The electrophysiological properties of the 6 classes of neurons have been extensively studied, including rhythmic bursting, bistability and postinhibitory rebound (Hartline et al., 1988; Hartline and Graubard, 1992). These intrinsic properties are subject to differential modulation in different neurons by identified neuromodulators that alter the motor pattern generated by the pyloric network (reviewed in Harris-Warrick et al., 1992c).

Bath application of the monoamine dopamine can dramatically alter the pyloric motor pattern (Fig. 1; Eisen and Marder, 1984; Flamm and Harris-Warrick, 1986a) through a combination of effects on synaptic efficacy (Johnson and Harris-Warrick, 1990; Johnson, et al., 1993a,b) and direct effects on the intrinsic properties of the pyloric network neurons (Flamm and Harris-Warrick, 1986b; Harris-Warrick and Flamm, 1987). Several neurons are directly excited by dopamine, and fire with 


\section{A. Control}

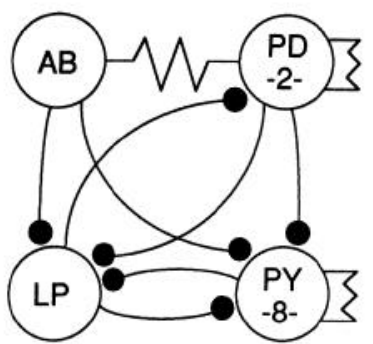

\section{Control}

PD

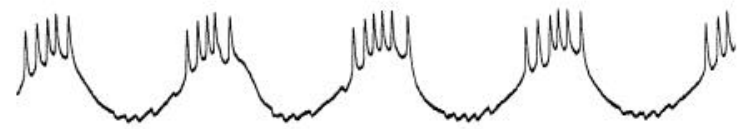

LP<smiles>C#CCCCC#CCCCCC#CCCCC#C</smiles>

PY

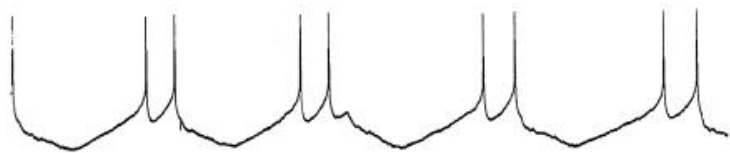

E. Control

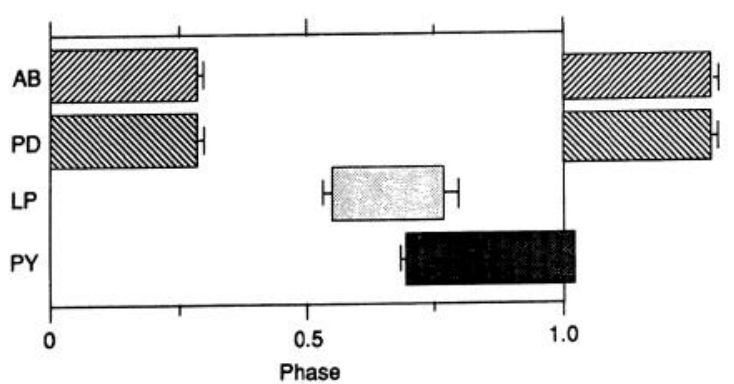

B. Dopamine

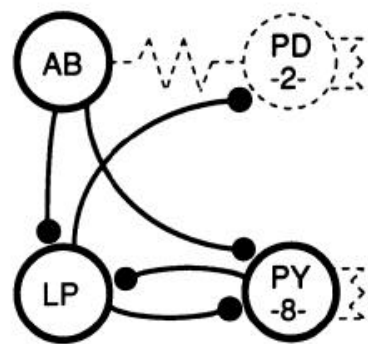

D. Dopamine
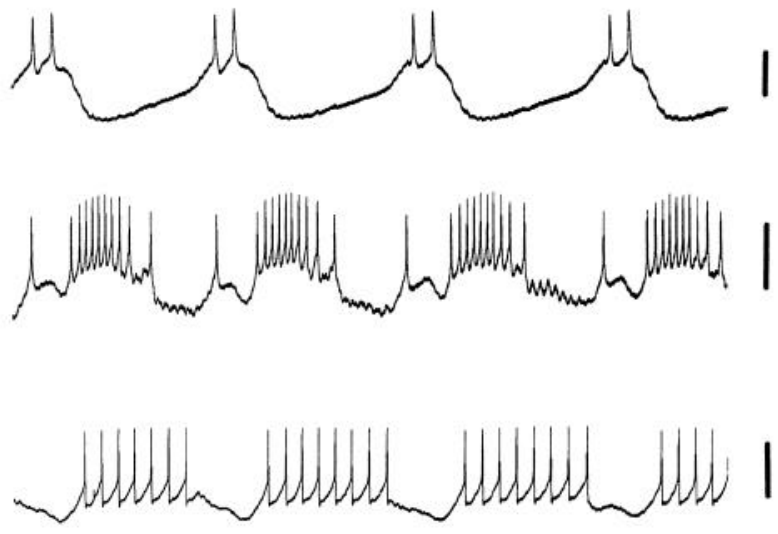

F. Dopamine

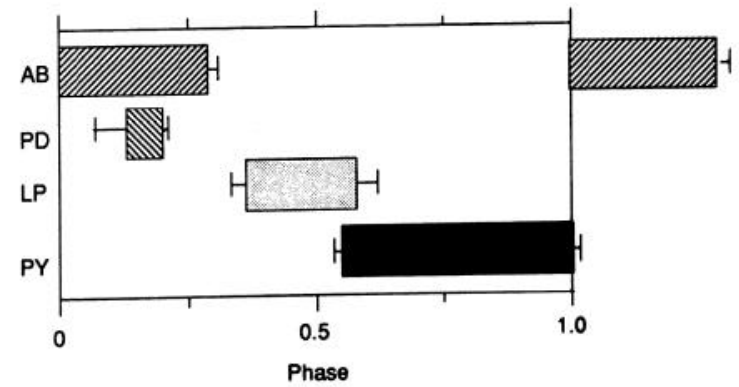

Figure 1. Effect of dopamine on the pyloric rhythm. A, Simplified network diagram of the pyloric network. Only four of the six major cell classes are shown, and some weak rectifying electrotonic connections are excluded. Inhibitory chemical synapses are represented by solid circles, while electrical coupling is represented by resistor symbols. $A B$, Anterior burster neuron; $P D$, pyloric dilator neuron; $L P$, lateral pyloric neuron; $P Y$, pyloric constrictor neuron. $B$, Summary of the effects of $10^{-4} \mathrm{M}$ dopamine on the pyloric network (Flamm and Harris-Warrick 1986a,b; HarrisWarrick et al., 1992; Johnson and Harris-Warrick, 1990). Excited cells and strengthened synapses are represented by thick lines, while inhibited cells and weakened synapses are represented by dashed lines. $C$ and $D$, Intracellular recording of pyloric rhythm under control conditions and in the presence of $10^{-4} \mathrm{M}$ dopamine. Vertical markers, $10 \mathrm{mV}$; horizontal marker, $1 \mathrm{sec} . E$ and $F$, Phase diagrams for activity of pyloric neurons under control conditions and in the presence of $10^{-4} \mathrm{M}$ dopamine. Phase 0 is defined by the first action potential recorded intracellularly from the $\mathrm{AB}$ neuron; other phases are defined as the fraction of the cycle in which the corresponding neuron is firing action potentials. The PY neurons were measured as a group from extracellular recordings of the PY nerve. Onset and offset values are means and SEs from three experiments.

high frequency, while other neurons are inhibited and decrease or cease firing (Flamm and Harris-Warrick, 1986b). Three identified neuronal types, including the eight pyloric constrictor (PY) neurons, show marked phase advances in their timing of activity within the pyloric cycle. This effect of dopamine has been explained by a loss of synaptic inhibition that these cells normally receive, allowing them to fire earlier in the pyloric cycle (Eisen and Marder, 1984). In this article, we show that in addition to 
changing synaptic strength, dopamine evokes a dramatic change in the rate of postinhibitory rebound that is intrinsic to some of the PY cells themselves. Some of these results have been presented in abstract form (Harris-Warrick, et al., 1992d).

\section{Materials and Methods}

Animals and drugs. California spiny lobsters, Panulirus interruptus, were obtained from Marinus Inc. (Los Angeles, CA) or from Don Tomlinson (San Diego, CA) and maintained in artificial sea water at $16^{\circ} \mathrm{C}$ until use. All drugs and salts were obtained from Sigma Chemical Co. (St. Louis, $\mathrm{MO}$ ).

Cell identification. The stomatogastric ganglion, along with its motor nerves and the associated commissural and oesophageal ganglia, was dissected from the animal as described by Selverston et al. (1976) and pinned in a Sylgard-lined dish. The preparation was continuously perfused at $3 \mathrm{ml} / \mathrm{min}$ with saline at $16^{\circ} \mathrm{C}$ of the following composition (mM): $\mathrm{NaCl} 479, \mathrm{KCl} 12.8, \mathrm{CaCl}_{2} 13.7, \mathrm{Na}_{2} \mathrm{SO}_{4} 3.9, \mathrm{MgSO}_{4} 10.0$, glucose 2.0, Tris base $11.1, \mathrm{pH} 7.35$ (Mulloney and Selverston, 1974). Extracellular recordings were made from identified motor nerves using bipolar suction or pin electrodes. After desheathing the STG, individual somata were impaled with fine microelectrodes $(15-20 \mathrm{M} \Omega, 3 \mathrm{M} \mathrm{KCl})$. The pyloric neurons were identified using three criteria: (1) 1:1 action potentials recorded intracellularly in the soma and extracellularly from an identified motor nerve, (2) characteristic phasing and synaptic input during the pyloric motor pattern, (3) characteristic shape of the membrane potential oscillations and action potentials in the pyloric rhythm.

Physiological recording. The response of the intact pyloric motor pattern to dopamine was recorded as described above, except that two or three neurons were impaled for intracellular recordings. Both intracellular and extracellular recordings were digitized on video tape. Dopamine $\left(10^{-4} \mathrm{M}\right)$ was bath applied, and the response of the preparation was recorded after 5-10 min. For phase measurements within the pyloric cycle, activity of the LP and PY cells was measured from extracellular recordings and thus represents the average activity of all eight PY neurons. Onset and offset phases were calculated as the fraction of the cycle period to the first or last spike of the indicated neuron type relative to the first spike in an intracellularly recorded $A B$ neuron.

Synaptic isolation of PY neurons. The PY cells were isolated from all detectable synaptic input as previously described (Flamm and HarrisWarrick, 1986b), using three steps: (1) removal of modulatory inputs from other ganglia with a $10^{-7} \mathrm{M}$ TTX/isotonic sucrose block placed in a small vaseline well on the stomatogastric nerve, the sole input nerve to the STG (Russell, 1979); (2) photoinactivation of the cholinergic PD and VD neurons by intracellular injection of 5,6-carboxyfluorescein and illumination with blue light (Miller and Selverston, 1979; Flamm and Harris-Warrick, 1986b); (3) blockade of remaining glutamatergic synapses with $5 \times 10^{-6} \mathrm{M}$ picrotoxin (Bidaut, 1980). The PY neurons were allowed to recover for at least $\mathrm{l} \mathrm{hr}$ after the photoinactivation before measurements were made. Although there might be additional sources of synaptic input to the PY neurons after this treatment (Nusbaum et al., 1992), such input was never observed. Some of the PY neurons are weakly electrically coupled (coupling coefficients typically 0.05 ; Johnson ct al., 1993a), but we saw no effect of this coupling in our experiments.

Stimulation of isolated PY neurons. Following isolation, a PY neuron was impaled with two microelectrodes, one of low resistance (7-9 MR, $3 \mathrm{M} \mathrm{KCl}$ ) for current injection and one of higher resistance (12-15 M $\Omega$ ) for voltage recording. DC current injection was used to hold each cell at a constant membrane potential of $-55 \mathrm{mV}$ during the entire experiment; this is similar to the normal resting potential of PY neurons under control conditions. Current injection protocols were driven by the pCLAMP program (Axon Instruments) using an Everex Step-386 microcomputer. Typically a series of $200 \mathrm{msec}$ hyperpolarizing prepulses with incrementing currents was given, followed immediately by a 650 msec depolarizing current pulse. The amplitude of this current pulse was adjusted throughout the experiment to give a constant depolarization to about $-45 \mathrm{mV}$, which is just above threshold for action potential generation in the PY neuron. This was necessary because under control conditions the synaptically isolated PY neuron is quiescent, while in the presence of dopamine the responsive cell depolarizes and fires tonically. The depolarizing pulse allowed us to compare the spike frequency in the presence and absence of dopamine under the same voltage conditions. Dopamine $\left(10^{-4} \mathrm{M}\right)$ was bath applied, and the PY cell response was measured after 8-10 min. All effects of dopamine on the isolated PY neuron were reversed after a $30 \mathrm{~min}$ washout with normal saline.
Voltage clamp. The synaptically isolated PY neuron was impaled with a low resistance current-injection electrode (4-7 $\mathrm{M} \Omega$ ) and a higher resistance voltage recording electrode (10-12 M $)$. The STG was bathed in saline containing $10^{-7} \mathrm{M}$ TTX, $20 \mathrm{~mm}$ TEA, and $200 \mu \mathrm{M} \mathrm{Cd^{21 }} 10$ greatly reduce non- $I_{\mathrm{A}}$ currents. The cell was voltage clamped using an Axoclamp-2A amplifier driven by pCLAMP software from an Everex Step-386 microcomputer. To isolate the transient potassium current, $I_{\mathrm{A}}$, from remaining contaminating currents, we took advantage of its voltage dependence for deinactivation and activation (Harris-Warrick, 1989; Graubard and Hartline, 1991; Tierney and Harris-Warrick, 1992; Hartline et al., 1993). The cell was held at $-50 \mathrm{mV}$, where $I_{\mathrm{A}}$ is mostly (but not completely) inactivated. Two series of $10 \mathrm{mV}$ voltage steps between $-40 \mathrm{mV}$ and $+20 \mathrm{mV}$ were delivered: the first series had no prestep, while the second series had a $200 \mathrm{msec}$ prestep to $-100 \mathrm{mV}$ to maximally deinactivate $I_{\mathrm{A}}$. Each series of steps was leak subtracted, and the first series (which evoked the residual non- $I_{\mathrm{A}}$ currents not blocked with our drugs) was digitally subtracted from the second series (which additionally possessed active $I_{\mathrm{A}}$ ). The resulting outward current was completely abolished by $4 \mathrm{~mm}$ 4-aminopyridine (4-AP), which selectively blocks $I_{\mathrm{A}}$ in STG neurons at this concentration (Graubard and Hartline, 1991; Tierney and Harris-Warrick, 1992). While this digital subtraction procedure gives a relatively pure $I_{\mathrm{A}}$, it also removes the contribution of active $I_{\mathrm{A}}$ at or below $-50 \mathrm{mV}$. This was typically less than $4 \%$ of the maximal conductance.

The inactivation kinetics and amplitudes of the two kinetic components of $I_{\mathrm{A}}$ were fit by the multiexponential curve-fitting routine CLAMPFIT within the pCLAMP package to the equation

$$
I=I_{0}+I_{f} e^{-t / r_{t}}+I_{s} e^{-t / \tau}
$$

where $I_{f}$ and $\tau_{f}$ are the maximal amplitude and time constant of the rapidly inactivating component of the current while $I_{\mathrm{s}}$ and $\tau_{\mathrm{s}}$ are the corresponding values for the slowly inactivating component of the current. These values were measured from identical points along the falling phase of the currents in all the cells.

The voltage dependence of activation of $I_{\mathrm{A}}$ was determined by converting the peak current to a peak conductance (assuming $E_{\mathrm{K}}=-86$ $\mathrm{mV}$; Hartline and Graubard, 1992), and fitting the resulting $g / V$ curvc to the Boltzmann equation

$$
g_{\mathrm{A}}=\bar{g}_{\mathrm{A}}\left(1 /\left(1+e^{-\left(V-V_{\mathrm{A}}\right) / s}\right)^{3}\right),
$$

where $\bar{g}_{\mathrm{A}}$ is the maximal conductance, $V_{\mathrm{A}}$ is the voltage at which halfmaximal activation of the individual gating steps occurs, $s$ is a slope factor, and a third order activation relation is assumed.

Steady state inactivation of $I_{\mathrm{A}}$ was measured from a holding potential of $-50 \mathrm{mV}$. Voltage presteps of $200 \mathrm{msec}$ duration were delivered at $10 \mathrm{mV}$ intervals from +20 to $-100 \mathrm{mV}$, to remove resting inactivation. Each prestep was followed by a step to $+20 \mathrm{mV}$, and the peak current was measured. The data were fit to the Boltzmann equation (with $n=$ 1) and scaled as a fraction of the calculated maximal current.

Mathematical model of PY neuron. We adapted the model of Golowasch (1991) and Buchholtz et al. (1992) for the LP neuron in the crab, Cancer borealis, for use with the PY neuron in the spiny lobster. This model has differential cquations representing the major currents present in STG neurons, including $I_{\mathrm{Na}}, I_{\mathrm{Ca}}, I_{\mathrm{K}(v)}, I_{\mathrm{K}(\mathrm{Ca})}, I_{\mathrm{A}}$, and $I_{\text {leak }}$. We changed the Buchholtz et al. model to better fit our experimental measurements of the dynamic response of the lobster PY neuron to depolarizing and hyperpolarizing steps, and to fit our voltage-clamp measurements of outward currents in this cell (Tierney and Harris-Warrick, 1992; L. Coniglio and R. M. Harris-Warrick, unpublished observations). The major changes from the Buchholtz et al. model are the following: (1) $I_{h}$ has been removed, as it is not present in a majority of PY neurons; (2) the maximal conductance, $\bar{g}_{\mathrm{A}}$, of $I_{\mathrm{A}}$ was increased, and the activation rate was assumed to be instantaneous; (3) the maximal conductances of $I_{\mathrm{K}(\mathrm{Ca})}$ and $I_{\mathrm{K}(1)}$ have been altered to fit experimental measurements in P. interruptus (Coniglio and Harris-Warrick, unpublished observations). The equations and parameter values used in this model are shown in Tables 2 and 3 .

Analysis of the dynamical responses of the model to sequential changes in the parameters of $I_{\mathrm{A}}, I_{\mathrm{ext}}$, and $I_{\mathrm{K}(\eta}$ was done using DsTooL, a dynamical systems toolkit (Back et al., 1992) on a SUN (SPARC 2) workstation. This software package is designed to aid the analysis of models beyond the simulation of individual trajectories. It facilitates exploration of the dependence of the complex dynamical system on its parameters by providing efficient numerical algorithms that can be invoked 
through a graphical interface. DsTool is available via anonymous ftp from an ftp server on macomb.cam.cornell.edu 132.236.122.12.

\section{Results}

Effect of dopamine on the ongoing pyloric rhythm

The normal pyloric rhythm is a triphasic motor pattern (Fig. 1). A simplified circuit diagram of some of the major neurons in the pyloric network is shown in Figure $1 A$. The clcctrically coupled anterior burster (AB) and two pyloric dilator (PD) neurons are the major pacemakers and inhibit the lateral pyloric (LP) and the eight pyloric constrictor (PY) cells. These cells recover from inhibition by postinhibitory rebound (PIR) and resume firing in two phases: first the LP, and, with a delay, the PY neurons (Fig. 1C,E). A subset of the PY cells in turn inhibits the LP cell, terminating its activity in the cycle. The PY cells continue to fire until inhibited by the next $\mathrm{AB} / \mathrm{PD}$ burst at the beginning of the next cycle. Thus, the phasing of activity of neurons in the pyloric motor pattern (Fig. $1 E$ ) depends on both the pattern of synaptic inhibition within the network and the different intrinsic rates of postinhibitory rebound in different cells (Miller, 1987; Johnson and Hooper, 1992).

As previously reported (Flamm and Harris-Warrick, 1986a), bath application of $10^{-4} \mathrm{M}$ dopamine evokes a number of changes in the pyloric rhythm. The AB, LP, and many of the PY neurons are excited and increase their firing frequencies, while the PD neurons are inhibited and decrease their firing frequencies (Fig. $1 B, D)$ and sometimes cease firing altogether. In addition, the LP and most of the PY neurons are phase advanced in their activity within the pyloric cycle (Fig. $1 F$ ). In three experiments, the LP onset phase was advanced by dopamine from $0.55 \pm$ 0.02 (SE) to $0.36 \pm 0.03$. Its termination of firing was also phase advanced from $0.77 \pm 0.03$ to $0.58 \pm 0.04$ by dopamine, due to the phase advance in onset of the activated PY cells that inhibit the LP. Finally, the onset of PY cell activity (measured extracellularly) was phase advanced from $0.69 \pm 0.01$ to 0.55 \pm 0.01 . All of these phase advances were statistically significant (paired Student's $t$ test, $p<0.05$ ). Intracellular recordings from the LP and PY neurons showed a marked increase in the rate of postinhibitory rebound following the rhythmic inhibition by the AB neuron: the LP and PY neurons repolarize with a steeper slope and thus resume firing earlier than under control conditions (compare Fig. 1C,D).

\section{Effect of dopamine on synaptically isolated PY neurons}

To examine the effect of dopamine on the intrinsic rebound properties of the PY cell, we studied 12 PY neurons that had been isolated from all detectable synaptic input in situ (sec Materials and Methods). Dopamine causes many, but not all, PY cells to depolarize from a quiescent state and spike tonically (Flamm and Harris-Warrick, 1986b). In our study, 10 of the 12 neurons tested were excited by dopamine; this heterogeneity is described in further detail below. To facilitate quantitative comparisons between dopamine and control states, all PY cells were held at $-55 \mathrm{mV}$ by constant current injection throughout the experiment. Instead of synaptic inhibition, we directly injected hyperpolarizing current pulses of $200 \mathrm{msec}$ duration and varying amplitudes, followed by a small depolarizing current pulse to a constant voltage slightly above the threshold for spike initiation; typically, this was set at $-45 \mathrm{mV}$. The rate of rebound was monitored by measuring the latency, or delay from the end of the hyperpolarizing prepulse to the first action potential, and the first interspike interval, or the time between the first and

\section{A. Control}

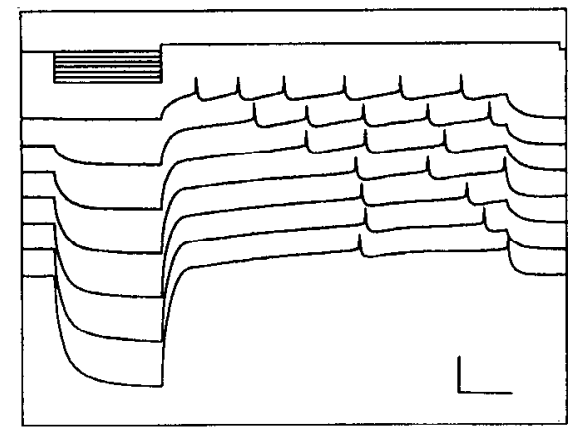

B. Dopamine

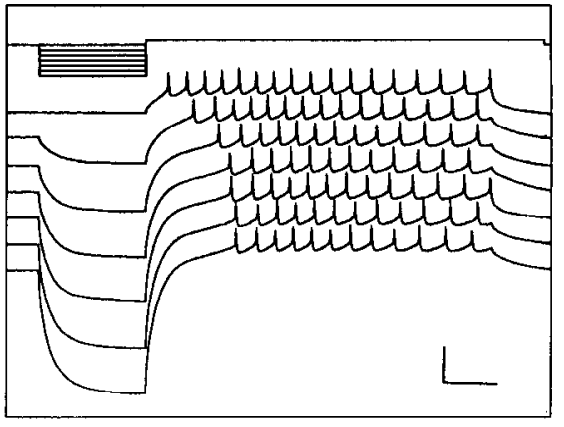

C. Wash

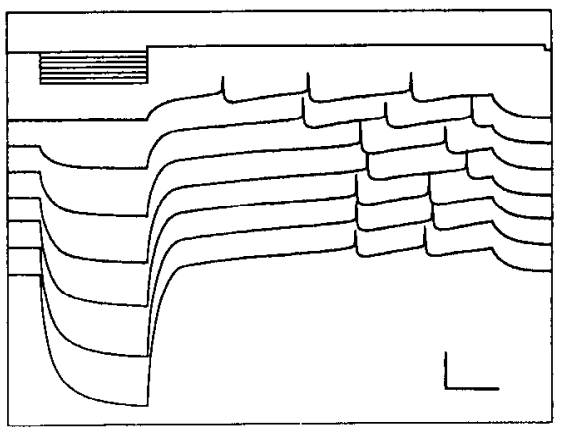

Figure 2. Effect of dopamine on postinhibitory rebound in a synaptically isolated PY neuron. $A$, Control; $B, 10^{-4} \mathrm{M}$ dopamine; $C, 30 \mathrm{~min}$ wash from dopamine. In each panel, the top trace indicates the current injection protocol. The neuron was held at $-55 \mathrm{mV}$ by current injection throughout the experiment; voltage traces are offset to enhance readability. A 200 msec prestep was delivered to hyperpolarize the cell between -60 and $-110 \mathrm{mV}$, followed by a depolarizing step to depolarize the cell to $-45 \mathrm{mV}$; the amplitudes of the current injections were adjusted during the experiment to maintain these voltage steps. Calibration: $20 \mathrm{mV}, 100 \mathrm{msec}$.

second spikes in the subsequent spike train (Tierney and HarrisWarrick, 1992).

Under control conditions, all 12 PY neurons showed similar firing characteristics. The latency to first spike is increasingly prolonged as the amplitude of the hyperpolarizing prestep is increased (Fig. 2A). At the end of the prestep, the cell begins to rebound passively, but then displays a slow and fairly linear ramp depolarization that delays the first spike. The ramp duration increases with increasing amplitudes of the hyperpolarizing prestep, up to about $-90 \mathrm{mV}$ (Fig. $3 A$ ). Beyond this voltage, the latency either remains relatively constant (Figs. $2 A, 3 A$ ), 

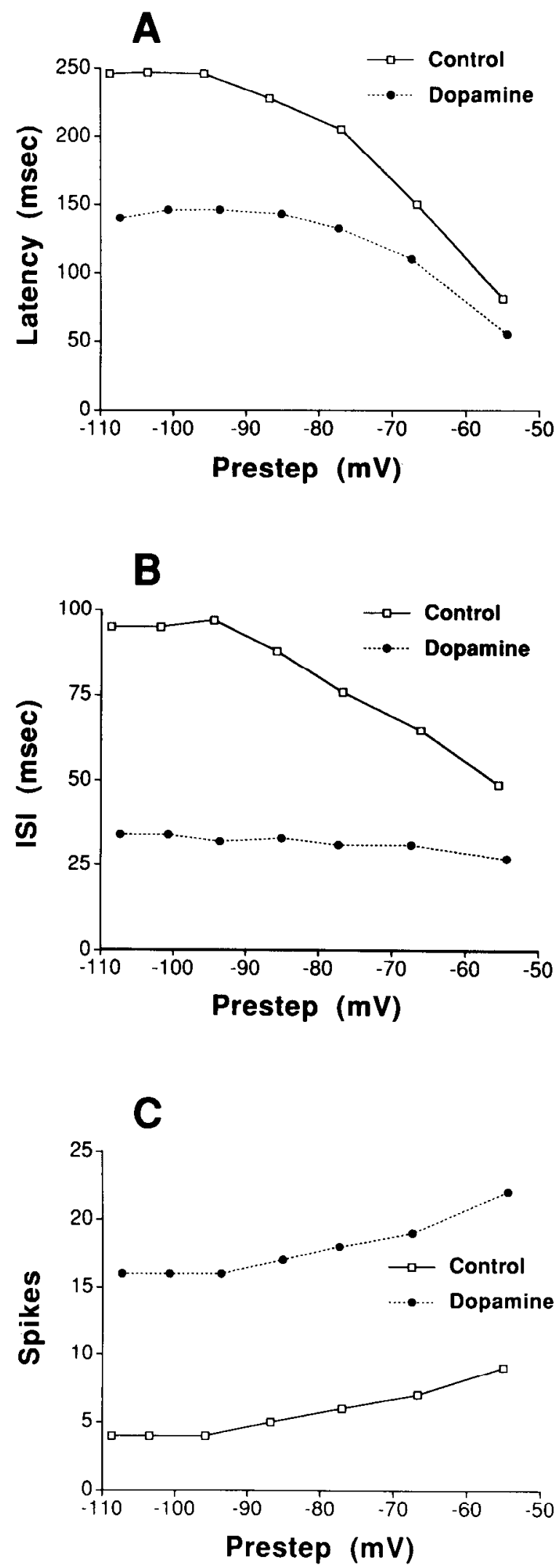

Figure 3. Effect of dopamine on postinhibitory rebound parameters in synaptically isolated PY neuron. These are representative data from a different preparation than shown in Figure 2. $A$, Delay to first spike. The time from the end of the hyperpolarizing prestep to the first action potential during the subsequent depolarizing step is shown as a function of the membrane potential at the end of the hyperpolarizing prestep. $B$, or increases much more slowly with voltage (see Fig. 81 ), mostly due to longer times for the initial passive rebound immediately after the end of the hyperpolarizing prestep.

In parallel, the spike frequency during the subsequent depolarizing step decreases with increasing amplitude of the hyperpolarizing prestep (Fig. $2 A$ ). This was measured as an increase in the first interspike interval (Fig. $3 B$ ). The frequency of tonic spiking is only slowly restored to its asymptotic value, and is typically not regained by the end of the $650 \mathrm{msec}$ depolarizing voltage step (Fig. 2A). The combination of increasing latency to first spike and reduced spike frequency during the spike train causes a decrease in total spikes during the depolarizing step with increasing amplitude of the hyperpolarizing prepulse (Figs. $2 A, 3 C$ ).

Bath application of DA $\left(10^{-4} \mathrm{M}\right)$ alters all these characteristics of postinhibitory rebound in a majority of cells tested (Figs. 2, 3 ). In the presence of dopamine, the latency to first spike is significantly reduced for all hyperpolarizing presteps (Figs. 2, $3 A$ ). This is accompanied by a marked reduction in the duration and an increase in the slope of the slow ramp depolarization following termination of the hyperpolarizing prestep (compare Fig. $2 A, B$ ). The latency to first spike has a similar voltage dependence to that seen in control, showing a steep rise with hyperpolarizing voltage to around $90 \mathrm{mV}$ (Fig. $3 A$ ) and a more shallow increase beyond this voltage. Dopamine also causes an increase in spike frequency during the subsequent depolarizing step (Fig. $2 B$ ). In the presence of dopamine, the interspike interval shows only a shallow dependence on the hyperpolarizing prestep voltage, and the cell fires at similar frequencies for all hyperpolarizing prepulses (Fig. $3 B$ ). As a consequence of the decrease in latency together with an increase in spike frequency, the total number of spikes during the depolarizing step is markedly increased during dopamine (Fig. $3 C$ ). All of these effects reverse following a $30 \mathrm{~min}$ washout of dopamine (Fig. 2C).

The eight PY cells are a heterogeneous set of neurons, with somewhat different electrophysiological properties and synaptic connections within the pyloric network (Hartline et al., 1987; R. Levini and R. Harris-Warrick, unpublished observations). Hartline et al. (1987) classified this group into two subgroups, PE and PL, based on their timing of activity following stimulation of the stomatogastric nerve, synaptic connections with other pyloric neurons, and sensitivity to an identified sensory/ modulatory input. Consistent with this physiological heterogeneity, we found that not all PY neurons respond equally to dopamine. Figure 4 shows a comparison of the effects of dopamine on latency to first spike and first interspike interval for 12 PY neurons after presteps to $-100 \mathrm{mV}$. Two of the 12 neurons did not respond at all to dopamine, while the remaining 10 neurons gave varying reductions ranging from $10 \%$ to $80 \%$ compared to control values of both latency and interspike interval. There was a tendency for the dopamine-responsive neurons to cluster into a weakly responding (10-30\%) and a strongly responding (40-60\%) group (Fig. 4); these correspond to the PE

Interspike interval $(I S I)$. The time between the first and second action potentials during the depolarizing step is shown as a function of the membrane potential at the end of the hyperpolarizing prestep. $C$, Spikes per step. The total number of action potentials fired during the depolarizing step is shown as a function of the membrane potential at the end of the hyperpolarizing prestep. $A-C$, Open squares, control; solid circles, $10^{-4} \mathrm{M}$ dopamine. 


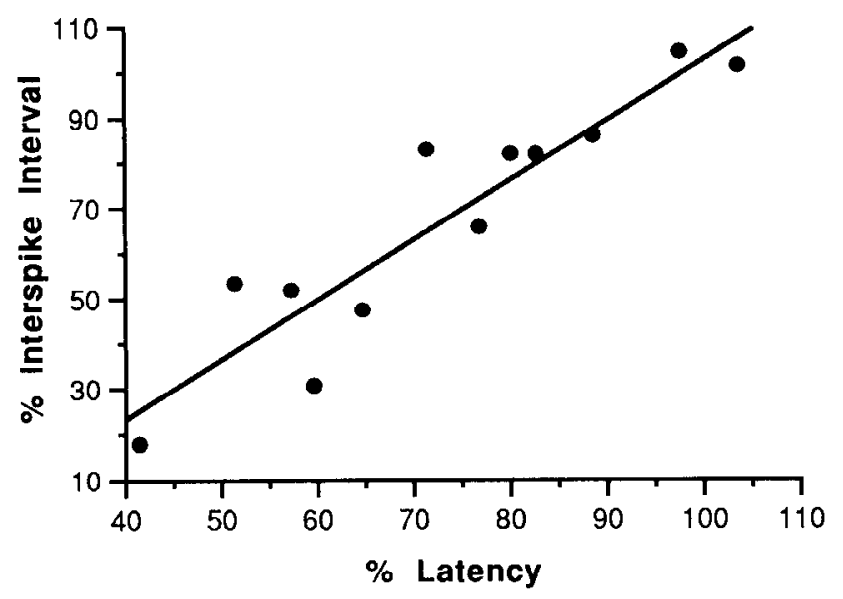

Figure 4. Comparison of the effect of dopamine on latency to first spike and interspike interval in 12 PY neurons. Each symbol represents a different PY neuron, and shows the interspike interval and delay to first spike in the presence of $10^{-4} \mathrm{M}$ dopamine as a percentage of the control values for that neuron. The line is a linear regression best fit through the data $\left(r^{2}=0.85\right)$.

and PL subtypes of Hartline et al. (1987; R. Levini and R. Harris-Warrick, unpublished observations). However, in this article we treat these dopamine-responsive cells as a single group, since the distribution of their dopamine sensitivity is not strictly bimodal, and all the dopamine-sensitive cells had similar qualitative responses to dopamine and our other experimental manipulations (see below). There is a strong correlation (correlation coefficient $=0.92$ ) for the two measurements of latency and interspike interval: cells that show large reductions in latency to first spike also show large reductions in first interspike interval, while cells showing weak responses to one measurement also show weak responses to the other. Regression analysis shows a linear relation between these variables (Fig. 4). This raises the possibility that a common mechanism may mediate both responses (see below).

We performed a statistical analysis of the effect of dopamine in nine responsive neurons following a hyperpolarizing prestep to $-100 \mathrm{mV}$ (Table 1). Calculations of the percent effect of dopamine on each cell showed that the amine evoked a reduction of the latency to first spike to $66 \pm 5 \%$ (SE) of control $(p$ $<0.01)$. Dopamine reduced the first interspike interval to 59 $\pm 8 \%$ of control values $(p<0.01)$. The similar percent reductions in latency and interspike interval induced by dopamine are not statistically different from one another $(p>0.05)$; again, this raises the possibility that a common mechanism might mediate both effects (see below). Finally, as a consequence of the two effects, the total number of spikes evoked during the depolarizing step to $-45 \mathrm{mV}$ was increased to $245 \pm 56 \%$ of control values $(p<0.05)$.

\section{Ionic mechanism of action of dopamine}

Based on theoretical simulations of STG neuron activity, Hartline (1979) proposed that the amplitude of the transient potassium current, $I_{\mathrm{A}}$, is a major factor determining the rate of postinhibitory rebound after inhibition in STG neurons. This outward current opens transiently only when the cell is depolarized following a hyperpolarization such as is evoked by synaptic inhibition. This arises because $I_{\mathrm{A}}$ is mostly inactivated at the PY's normal resting potential $(-55 \mathrm{mV})$, but the inactivation can be removed by brief $(<200 \mathrm{msec})$ hyperpolarizations
Table 1. Effect of dopamine on postinhibitory rebound in PY cells

\begin{tabular}{lcc} 
Measurement & Control & Dopamine \\
\hline Latency to Ist spike, msec & $261 \pm 25$ & $176 \pm 21^{* *}$ \\
Interspike interval, msec & $99 \pm 17$ & $53 \pm 8^{*}$ \\
Total spikes per step & $7.7 \pm 1.5$ & $15.4 \pm 2.6^{* *}$
\end{tabular}

$n=9 ;$ values are given as mean \pm SEM. Statistical significance from control as calculated by paired Student's $t$ test.

$* p<0.05$.

${ }^{* *} p<0.01$.

below $-50 \mathrm{mV}$, with maximal deinactivation at -80 to -90 mV (Harris-Warrick, 1989; Graubard and Hartline, 1991; Tierney and Harris-Warrick, 1992). Subsequent depolarization activates the outward current transiently with an apparent activation threshold around -60 to $-50 \mathrm{mV}$. We tested the hypothesis that dopamine modulation of $I_{\mathrm{A}}$ changes the isolated PY's posthyperpolarization rebound characteristics.

\section{Input resistance measurements}

We measured the input resistance of eight dopaminc-rcsponsive PY neuron with small $(10 \mathrm{mV})$ hyperpolarizing steps from -50 $\mathrm{mV}$. In these experiments, the input resistance was $33 \pm 11 \mathrm{M} \Omega$ under control conditions, increased to $43 \pm 14 \mathrm{M} \Omega$ during dopamine superfusion, and recovered to $34 \pm 12 \mathrm{M} \Omega$ after a 30 min wash. Statistical analysis comparing the percent changes in each cell showed that dopamine evoked a $38 \pm 13 \%$ increase in input resistance $(p<0.03 ; n=8)$. This suggests that dopamine acts on its responsive neurons by a net conductance decrease mechanism.

\section{Voltage-clamp measurements}

We analyzed the effects of dopamine on $I_{\mathrm{A}}$ in dopamine-responsive PY neurons using two-electrode voltage-clamp techniques (Fig. 5). $I_{\mathrm{A}}$ was isolated by a combination of selective pharmacological block of other currents and digital subtraction of currents activatcd from a holding potential of $-50 \mathrm{mV}$, where $I_{\mathrm{A}}$ is mostly inactivated.

Under control conditions, $I_{\wedge}$ activates with voltage steps above -60 to $-50 \mathrm{mV}$, and increases with depolarization (Fig. $5 A, D$ ). The current is transient, and decays due to inactivation during a maintained depolarizing voltage step. The conductance/voltage relation (Fig. $5 D$ ) was constructed from the peak currents evoked by each voltage step. This curve shows a typical voltage dependence for activation of $I_{\mathrm{A}}$, and was fit to the Boltzmann equation with third order activation (Eq. 2, Materials and Methods). This fit shows half-maximal activation of each of the three individual gating steps at $-43 \mathrm{mV}$, leading to half-maximal activation of the peak current at $-21 \mathrm{mV}$. Once inactivated, $I_{A}$ must be deinactivated by hyperpolarization. The voltage dependence of steady state inactivation is well fit by the Boltzmann equation with a single exponential (Fig. $5 D$ ). The voltage for half-inactivation under control conditions was $-62.5 \pm 2.7 \mathrm{mV}$ $(n=6)$. Note that there is a significant region of overlap between the activation and inactivation curves, suggesting that $I_{\Lambda}$ is partially activated at the normal resting potential $(-50$ to -55 $\mathrm{mV}$ ).

Although the peak currents of $I_{\mathrm{A}}$ were well clamped, the activation kinetics were too rapid to be fit reliably. The kinetics of inactivation during maintained depolarizing steps are complex, showing two decaying exponential components. We fit the 

A. Control
B. Dopamine
C. Wash

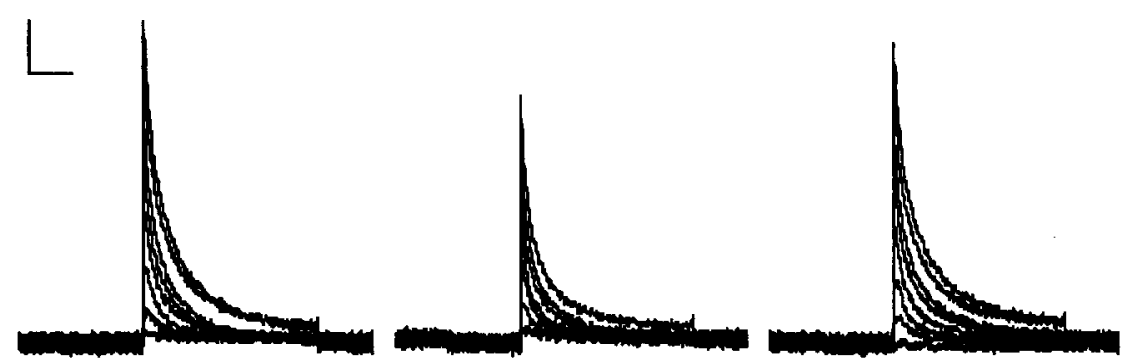

D.

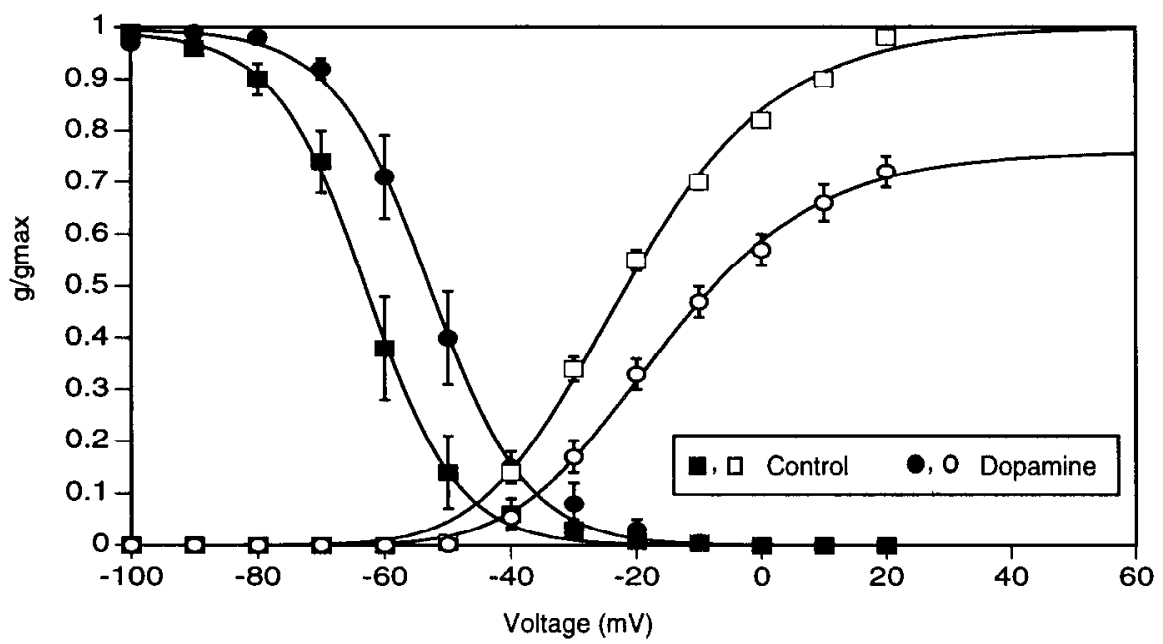

Figure 5. Voltage clamp analysis of the effect of dopamine on the transient $\mathrm{K}^{+}$current, $I_{\mathrm{A}}$, in a PY neuron. Current traces of $I_{\mathrm{A}}$ under control conditions $(A)$, in the presence of $10^{-4} \mathrm{M}$ dopamine $(B)$, and after a $30 \mathrm{~min}$ wash $(C)$. Each series represents current responses to voltage steps at $10 \mathrm{mV}$ increments from -50 to $+20 \mathrm{mV}$. $I_{\mathrm{A}}$ was isolated by pharmacological blockade and digital subtraction as described in Materials and Methods. Time marker, $125 \mathrm{msec}$; current marker, $50 \mathrm{nA}$. D. Conductance/voltage curves for activation and inactivation of $I_{\mathrm{A}}$ under control conditions (squares) and in $10^{-4} \mathrm{M}$ dopamine (circles). Peak activation following a maximally deinactivating prestep to $-100 \mathrm{mV}$ is shown in curves with open symbols. Conductance was calculated assuming $E_{\mathrm{K}}=-86 \mathrm{mV}$ (Eisen and Marder, 1982; Hartline and Graubard, 1992). Values are means and SEs from seven experiments, calculated as a fraction of the calculated maximal conductance under control conditions in each experiment. The curves are best fits of Equation 2 in Materials and Methods, with the following parameters. Control, $g_{\mathrm{A}}=2.24 \mu \mathrm{S} ; V_{\mathrm{A}}=-43$ $\mathrm{mV} ; s=-16 \mathrm{mV}$. Dopamine, $\bar{g}_{\mathrm{A}}=1.65 \mu \mathrm{S} ; V_{\mathrm{A}}=-37.5 \mathrm{mV} ; s=-15.4 \mathrm{mV}$. Steady state inactivation (measured from varying prestep voltages during a step to $+20 \mathrm{mV}$ ) is shown in curves with solid symbols, and was calculated as described in Materials and Methods. $n=6$ for control and $n=3$ for dopamine. The curves are best fits of the Boltzmann equation with $n=1$ and the following parameters. Control, $V_{0.5}=-63 \mathrm{mV} ; s=$ $7.2 \mathrm{mV}$. Dopamine, $V_{0.5}=-53 \mathrm{mV} ; s=7.6 \mathrm{mV}$.

falling phase of the current after steps to $+20 \mathrm{mV}$ to a double exponential curve described by Equation 1 (see Materials and Methods) to determine the time constants and amplitudes of the rapidly and slowly inactivating components of the current. The time constants were $25 \pm 4 \mathrm{msec}$ and $107 \pm 11 \mathrm{msec}$ ( $n$ $=7$; Fig. $6 B)$. The slow component is larger $(122 \pm 11 \mathrm{nA}$ at $+20 \mathrm{mV})$ than the fast component $(70 \pm 9 \mathrm{nA}$ at $+20 \mathrm{mV})$; the ratio of the amplitude of the slow to fast component is $1.75: 1$ (Fig. 6C).

Dopamine reduces $I_{\mathrm{A}}$ at all voltages (compare Fig. $5 \mathrm{~A}, \mathrm{~B} ; \mathrm{g} / \mathrm{V}$ curve in Fig. $5 D$ ). In seven PY cells, dopamine evoked a $30 \%$ decrease in peak current at $0 \mathrm{mV}(p<0.02)$. There was a shift in the voltage dependence of activation of $I_{\mathrm{A}}$ toward more depolarized voltages in the presence of dopamine. Fits of the data to the Boltzmann equation (Eq. 2 in Materials and Methods; Fig. 5D) show a shift in half-maximal activation of the three activation gating steps from $-43 \mathrm{mV}$ in control to $-37.5 \mathrm{mV}$ in the presence of dopamine, leading to half-maximal activation of the peak current at $-17 \mathrm{mV}$, compared to $-21 \mathrm{mV}$ under control conditions. The decreases in peak amplitude evoked by dopamine were statistically significant at all voltages $(p<0.02)$. In keeping with the heterogeneity of physiological responses of different PY neurons to dopamine (Fig. 4), there was heterogeneity in the dopamine-evoked reduction of $I_{\mathrm{A}}$ in different PY cells: some cells showed strong reductions of $60 \%$ in peak current at $0 \mathrm{mV}$, while others showed more modest reductions of 15$25 \%$ in peak current. Interestingly, the steady-state inactivation curve was also shifted to the right by dopamine. In three experiments, the voltage for half-maximal inactivation was shifted from $-57.3 \pm 3.2 \mathrm{mV}$ under control conditions to $-53.3 \pm 2.2$ $\mathrm{mV}$ in the presence of $10^{-4} \mathrm{M}$ dopamine; however, with our small sample size, this shift did not achieve statistical significance. The effects of dopamine reversed after a $30 \mathrm{~min}$ wash (Fig. 5C).

Analysis of the kinetics of inactivation of $I_{\mathrm{A}}$ showed a selective effect of dopamine on the amplitude of the slowly inactivating 


\section{A}

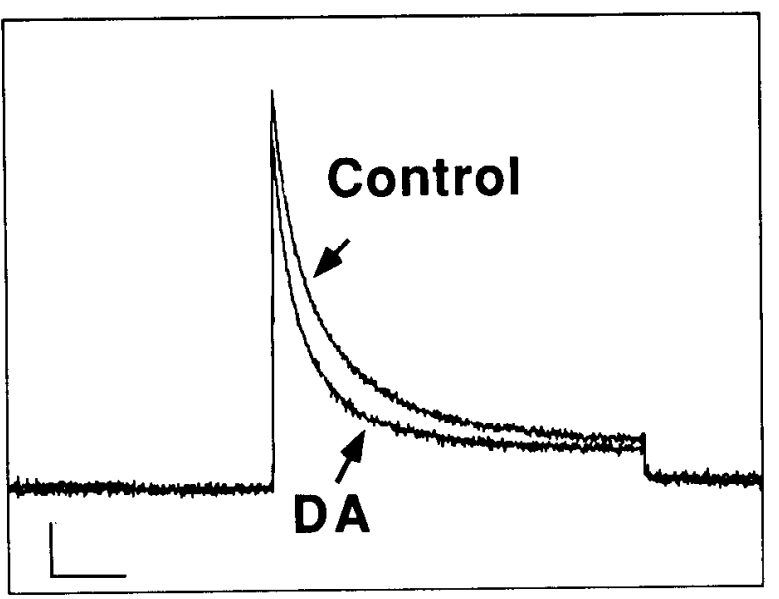

B
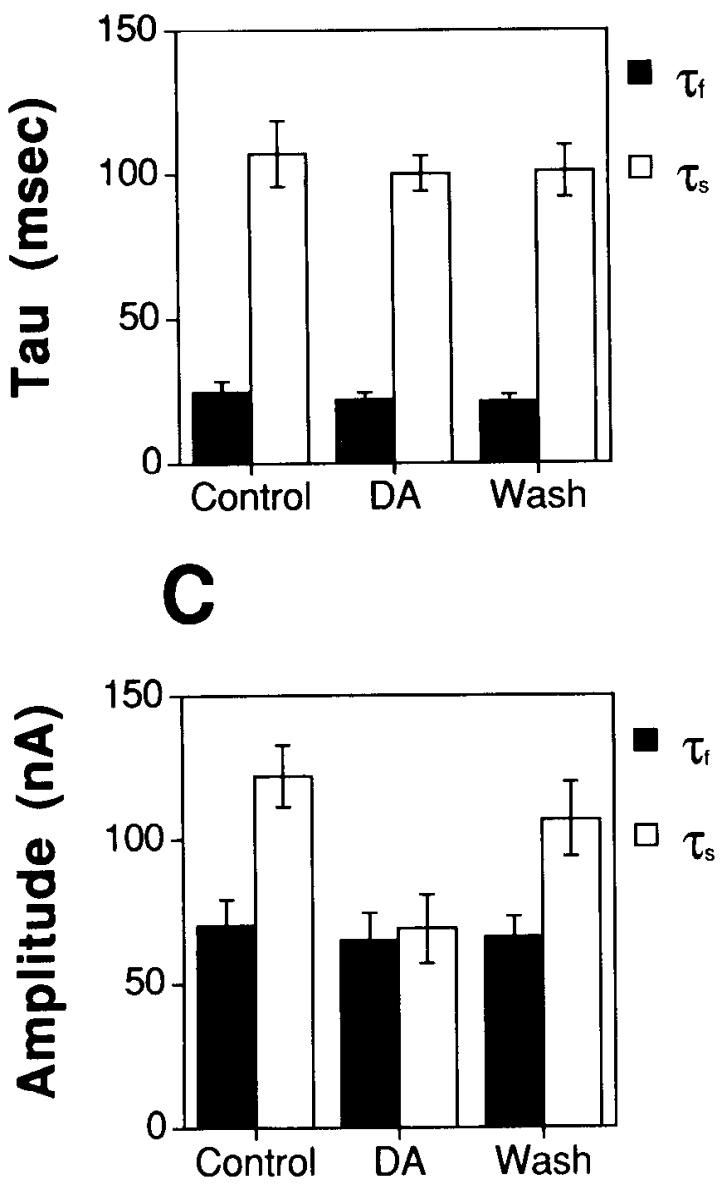

Figure 6. Dopamine modulation of the slowly inactivating component of $I_{\mathrm{A}} . A$, Superposition of $I_{\mathrm{A}}$ evoked by voltage step to $+20 \mathrm{mV}$ under control conditions and in the presence of $10^{-4} \mathrm{M}$ dopamine. The trace in the presence of dopamine is smaller and inactivates more rapidly than the control trace. Time marker, $100 \mathrm{msec}$; current marker, $50 \mathrm{nA}$. $B$, Lack of effect of dopamine on the time constants for inactivation of $I_{\mathrm{A}}$, measured during a step to $+20 \mathrm{mV}$. The time constants were obtained by fitting the biexponential relation of Equation 1 (Materials and Methods) to the falling phase of the currents. The fast time constant is component of the current. Inspection of the current traces suggested that $I_{\mathrm{A}}$ inactivates more rapidly during a maintained voltage step in the presence of dopamine (Fig. 6A). However, when the decaying phase of the current was fit to the biexponential relation in Equation 1 (Materials and Methods), dopamine did not significantly change the time constants for inactivation of either the rapidly or slowly inactivating components of $I_{\mathrm{A}}$ (Fig. $6 \mathrm{~B}$ ); these were $25 \perp 4 \mathrm{msec}$ and $107 \perp 11 \mathrm{msec}$ in control and $22 \pm 2 \mathrm{msec}$ and $100 \pm 6 \mathrm{msec}$ in DA $(p>0.2 ; n$ $=7$ ). Instead, dopamine significantly reduced the amplitude of the slowly inactivating component by $43 \%$, from $122 \mathrm{nA}$ to 69 $\mathrm{nA}$ at $+20 \mathrm{mV}(p<0.001)$; the amplitude of the rapidly inactivating component was unaltered ( $p>0.3$; Fig. $6 C$ ). This effect reversed upon a $30 \mathrm{~min}$ washout from dopamine. Thus, dopamine reduces $I_{\mathrm{A}}$ in PY cells by selectively reducing the maximal conductance of its slowly inactivating component and slightly shifting its voltage dependence for activation (and to a lesser extent inactivation) to more depolarized voltages. As a consequence, the current is smaller at peak amplitude at any voltage and inactivates significantly more rapidly.

\section{Effect of 4-aminopyridine and cesium}

Further evidence for the importance of $I_{\mathrm{A}}$ in dopamine modulation of postinhibitory rebound in the PY cclls comcs from application of the selective $I_{\mathrm{A}}$ channel blocker 4 -aminopyridine (4-AP). We and others have previously shown that 4-AP selectively blocks $I_{\mathrm{A}}$ with no detectable effect on other $\mathrm{K}^{+}$currents (including $I_{\mathrm{K}(n)}$ and $\left.I_{\mathrm{K}(\mathrm{Ca})}\right)$ in Panulirus STG neurons (HarrisWarrick, 1989; Graubard and Hartline, 1991; Tierney and Harris-Warrick, 1992). Bath application of low concentrations of 4-AP to the intact pyloric network evokes changes in PY activity similar to those seen during application of dopamine: the PY neurons fire at higher frequency and are phase advanced relative to the pacemaker group in the pyloric rhythm (Tierney and Harris-Warrick, 1992). When 4-AP is bath applied to a quiescent, synaptically isolated PY neuron, the cell responds as it does to dopamine by depolarizing and firing tonically at high frequency (Tierney and Harris-Warrick, 1992). Here, we look at the effect of 4-AP on the isolated PY neuron's postinhibitory rcbound characteristics. When $4 \mathrm{~mm}$ 4-AP (sufficient to abolish $I_{\mathrm{A}}$; Tierney and Harris-Warrick, 1992) is bath applied, a strong reduction in the latency to first spike following hyperpolarizing prepulses is seen (compare Fig. $7 A, B$ ). The delayed slow ramp depolarization is completely eliminated, leaving a simple exponential recovery to the initiation of tonic spiking. When measured following a $-100 \mathrm{mV}$ prestep, 4-AP reduced the latency to first spike to $30 \pm 3 \%$ of control values $(p<0.001 ; n=4)$. The voltage dependence of the latency to first spike is also reduced, reflecting only the passive electrical recovery from the hyperpolarizing presteps (Fig. 8A). In parallel, 4-AP evokes a

the first column under each condition, while the slow time constant is the second column. Dopamine (middle set of columns) does not change the values of $\tau_{f}$ or $\tau_{s}$ compared to control (left set of columns) or wash (right set of columns). $C$, Effect of dopamine on the amplitudes of the slowly and rapidly inactivating components of $I_{\mathrm{A}}$ measured during a voltage step to $+20 \mathrm{mV}$. Amplitudes were obtained by biexponential curve fits of Equation 1 (Materials and Methods) to the decaying portions of the current traces and show a selective reduction of the slowly inactivating component during dopamine, with no effect on the rapidly inactivating component. In $B$ and $C$, the values are means and SEs from seven cells. 


\section{A. Control}

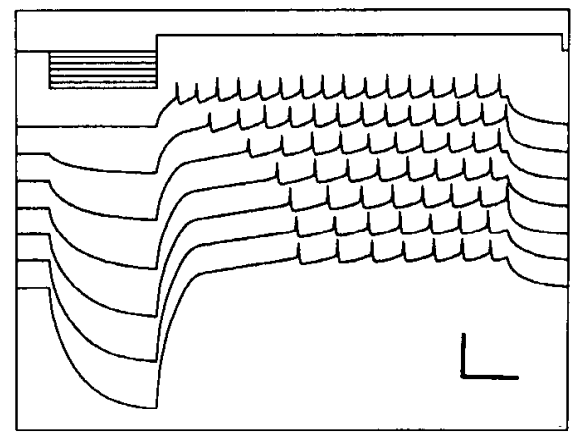

\section{B. 4-AP}

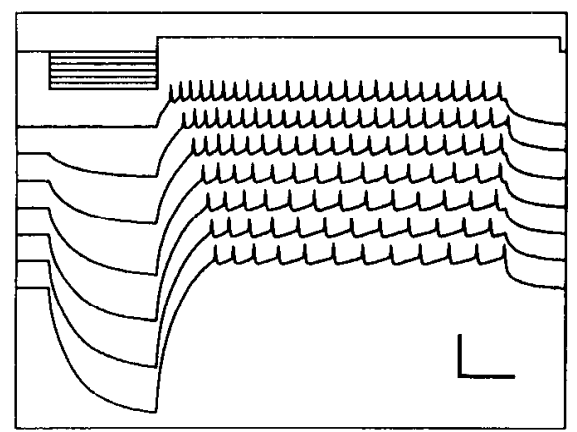

C. 4-AP + DA

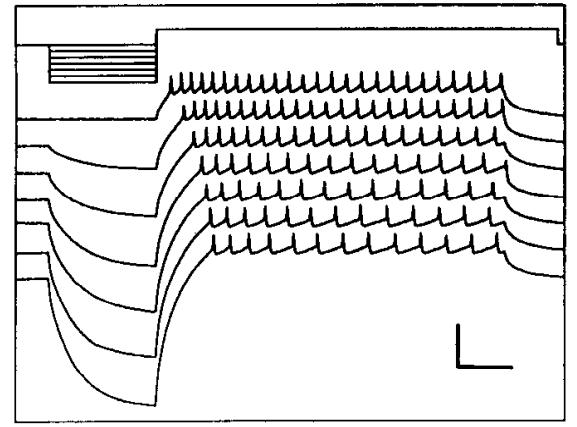

Figure 7. 4-Aminopyridine mimics and occludes the effects of dopamine on synaptically isolated PY neurons. $A$, Control. $B$, During $4 \mathrm{~mm}$ 4-AP. $C$, During superfusion with both $4 \mathrm{mM} 4$-AP and $10^{-4} \mathrm{M}$ dopamine, about 10 min after the recordings in $B$. Current injection protocols and recordings were performed as described in the legend to Figure 2. Time marker, $100 \mathrm{msec}$; voltage marker, $20 \mathrm{mV}$.

significant increase in spike frequency during the subsequent depolarizing step (Fig. $7 \mathrm{~B}$ ). Following a prestep to $-100 \mathrm{mV}$, the first interspike interval in the train was reduced to $35 \pm 4 \%$ of control values ( $p<0.005 ; n=4)$. Again, the voltage dependence of the interspike interval is greatly reduced, suggesting an important role for $I_{\mathrm{A}}$ in determining this effect (Fig. 8B). As a consequence of these dual actions, 4-AP increased the total number of spikes during the depolarizing step (Fig. $7 B$ ), to 334 $\pm 116 \%$ of control values. These results show that the effects of 4-AP on postinhibitory rebound resemble those of DA. The effect of 4-AP is more pronounced than that of DA because 4-AP (at 4 mm) abolishes $I_{\mathrm{A}}$, whereas DA reduces it by only $30 \%$.
In the presence of $4 \mathrm{~mm} 4-\mathrm{AP}$, dopamine has little or no additional effect on postinhibitory rebound in the PY cells (Fig. $7 C$ ). The latency to first spike (Fig. $8 A$ ) and interspike interval (Fig. $8 B$ ) are not significantly changed when comparing 4-AP + dopamine to 4-AP alone. Statistical comparisons were made using hyperpolarizing presteps to $-100 \mathrm{mV}$. The mean latency to first spike was reduced to $30 \pm 3 \%$ of control values by $4-\mathrm{AP}$ and unchanged at $29 \pm 4 \%$ when DA was added with 4-AP ( $p$ $>0.35 ; n=4)$. The mean interspike interval decreased from $35 \pm 6 \%$ of control values in 4 -AP to $31 \pm 6 \%$ when DA was further added, a nonsignificant change $(p>0.05 ; n=4)$. The increase in number of spikes per step was not significantly changed, from $334 \pm 116 \%$ in 4 -AP to $382 \pm 128 \%$ in 4 -AP + dopamine $(p>0.05 ; n=4)$. 4-AP also abolished the increase in input resistance evoked by dopamine in the PY cells: in the four cells we tested with 4-AP, the input resistance in $4 \mathrm{~mm}$ 4-AP was $19 \pm 9 \mathrm{M} \Omega$; addition of dopamine with 4-AP caused a nonsignificant increase to $21 \pm 9 \mathrm{M} \Omega(p>0.1)$. These results show that 4-AP occludes the effects of dopamine on postinhibitory rebound in the PY neuron.

The hyperpolarization-activated inward current, $I_{h}$, is a very slowly activated inward current that regulates the rate of postinhibitory rebound in some systems (Angstadt and Calabrese, 1989; Harris-Warrick et al., 1992d). This current is present in a subset of stomatogastric neurons, where it evokes a slow depolarizing voltage sag during a prolonged (4 sec) constant amplitude hyperpolarizing current pulse (Golowasch, 1991; Kiehn and Harris-Warrick, 1992a,b; Coniglio and Harris-Warrick, unpublished observations). However, such a sag voltage was not detectable in the majority $(8 / 11)$ of PY neurons. In three PY cclls, a small dcpolarizing sag was observed during 4 sec constant hyperpolarizing current injection, but only at nonphysiological voltages (below $-100 \mathrm{mV}$ ). Dopamine did not change the amplitude of the hyperpolarization-induced voltage sag in these three cells (data not shown). Direct efforts to detect $I_{h}$ in PY neurons during prolonged $(1-5 \mathrm{sec})$ hyperpolarizing voltage steps under voltage clamp have also been unsuccessful. However, it is possible that $I_{h}$ is localized in the distal neuropil regions of these cells, where it would be hard to detect from our soma recordings. Thus, we used pharmacological antagonism to study the possible role of $I_{h}$ in PY cells. $I_{h}$ is sensitive to low concentrations of extracellular $\mathrm{Cs}^{+}$(McCormick and Pape, 1990; Golowasch and Marder, 1992; Golowasch et al., 1992; Kiehn and Harris-Warrick, 1992a,b). Accordingly, we studied the effects of $\mathrm{Cs}^{+}$on postinhibitory rebound in the PY neuron. In three PY cells, bath application of 3-5 $\mathrm{mM} \mathrm{Cs}^{+}$(sufficient to abolish $I_{h}$ in STG neurons; Golowasch et al., 1992; Kichn and HarrisWarrick, 1992b; Coniglio and Harris-Warrick, unpublished observations) very slightly increased the latency to first spike from $175 \pm 13$ to $181 \pm 14 \mathrm{msec}(n=3 ; p=0.04)$, and insignificantly prolonged the first interspike interval from $65 \pm 17$ to $69 \pm 21$ $\operatorname{msec}(p>0.4)$ following a prestep to $-100 \mathrm{mV} . \mathrm{Cs}^{+}$application did not significantly affect the PY neuron's response to dopamine. In three PY cells, dopamine reduced the latency to first spike to $65 \pm 10 \%$ of control in the absence of $\mathrm{Cs}^{+}$, and to 74 $+7 \%$ in the presence of $3-5 \mathrm{~mm} \mathrm{Cs}^{+}(p>0.2)$. Similarly, dopamine reduced the first interspike interval to $57 \pm 13 \%$ of control values in the absence of $\mathrm{Cs}^{+}$and to $70 \pm 13 \%$ in the presence of 3-5 $\mathrm{mM} \mathrm{Cs}^{+}(p>0.15)$. Thus, while $I_{h}$ may contribute marginally to postinhibitory rebound of a subset of PY neurons, it does not appear to be a major target of dopamine action in this cell type. 

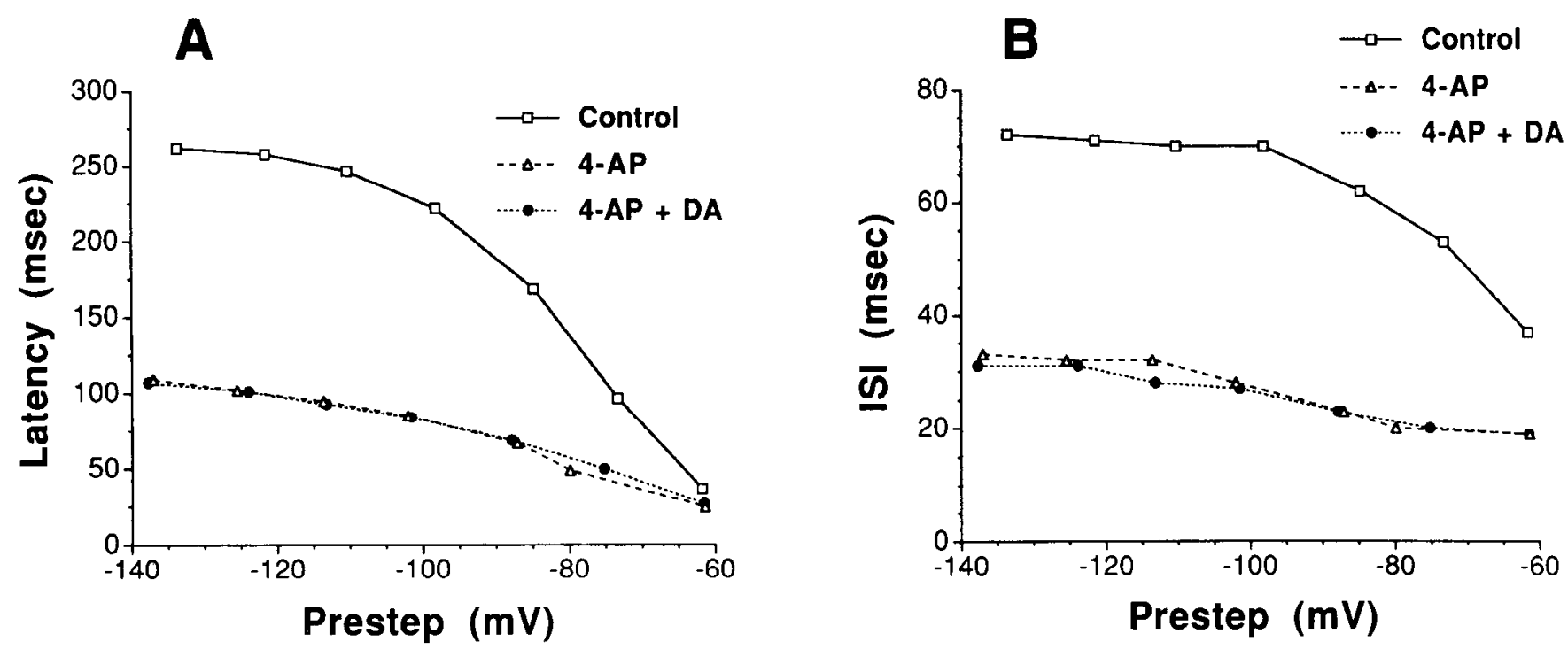

Figure 8. Quantitation of the effect of 4-aminopyridine and dopamine on postinhibitory rebound in synaptically isolated PY neurons. $A$, Delay to first spike following a hyperpolarizing prepulse is plotted as a function of the membrane potential at the end of the prepulse. $B$, The first interspike interval (ISI), calculated as the time between the first and second action potential during the depolarizing pulse, plotted as a function of the membrane potential at the end of the hyperpolarizing prepulse. Squares, Control. Triangles, $4 \mathrm{~mm} 4-\mathrm{AP}$. Solid circles, $10^{-4} \mathrm{M}$ dopamine plus 4 mM 4-AP.

\section{Mathematical model of $P Y$ response to dopamine}

To study whether the measured reduction in $I_{\mathrm{A}}$ is qualitatively sufficient to explain the changes in postinhibitory rebound evoked by dopamine in the dopamine-responsive PY neuron, we analyzed a mathematical model of this neuron. Our model is based on the experimental work of Golowasch and Marder (1992) and the model developed by Buchholtz et al. (1992) of the LP neuron from the crab, Cancer borealis, with modifications necessary to fit our experimental data. The model is a single compartment conductance-based model containing the following currents: a Hodgkin-Huxley sodium current $\left(I_{\mathrm{Na}}\right)$, a delayed rectifier potassium current $\left(I_{\mathrm{K}(1)}\right)$, a calcium-activated potassium current $\left(\mathrm{I}_{\mathrm{K}(\mathrm{Ca})}\right)$, a potassium A current $\left(I_{\mathrm{A}}\right)$, a calcium current $\left(I_{\mathrm{Ca}}\right)$, and a leak current $\left(I_{L}\right)$. Since the sag current, $I_{h}$, is not detectable in a majority of PY neurons, it was removed from the Buchholtz et al. model of the LP cell to produce this model for the dopamine-responsive PY cell. Additional modifications to the model of Buchholtz et al. are described below. The full set of equations used to describe the model, along with the values of fixed parameters, are given in Tables 2 and 3.

Our model defines a multidimensional parameter spacc within which the PY neuron is located; the axes of this space correspond to the variable parameters of the model, such as the maximal conductance of an ion current or the reversal potential for an ion. The activity profile of the PY neuron then depends on its location in this multidimensional parameter space: with certain ranges of parameters the cell is quiescent, but with other ranges the cell fires tonically or shows bistability. In the multidimensional parameter space of the model, there is a surface, called a bifurcation, that divides the tonic firing region from the region in which the cell is quiescent. Dopamine acts by altering the parameters of the PY neuron to cross this bifurcation surface from the quiescent to the tonically active region. Our problem is to determine which parameters are altered by dopamine. Variations of many parameters of different ionic conductances are capable of moving the model cell across this bifurcation surface, though the sensitivity to variations of each parameter differs. At the boundary between the firing and quiescent regions, the tonic firing slows smoothly until its frequency is zero. Thus, the distance from this boundary is correlated with the frequency of tonic spiking. However, the rate of variation of the frequency with variations in individual parameters is not uniform.

We adjusted the parameters of this model so that its "control" conditions approximate those of the synaptically isolated PY cell from $P$. interruptus. We have made a series of measurements of the maximal conductance of $I_{\mathrm{A}}$, the calcium activated potassium current $I_{\mathrm{K}(\mathrm{Ca})}$ and the delayed rectifier current $I_{\mathrm{K}(n)}$ in PY neurons from $P$. interruptus to establish baseline parameters for the model cell. The maximal conductances (using the input capacitance to correct for cell size) were $1.2 \pm 0.1 \mu \mathrm{S} / \mathrm{nF}$ and $0.7 \pm 0.09 \mu \mathrm{S} / \mathrm{nF}$ for the slow and fast components of $I_{\mathrm{A}}, 5.9$ $\pm 0.6 \mu \mathrm{S} / \mathrm{nF}$ for $I_{\mathrm{K}(\mathrm{Ca})}$, and $0.59 \pm 0.08 \mu \mathrm{S} / \mathrm{nF}$ for $I_{\mathrm{K}(n)}(n=8)$ The voltage for half-activation of the individual gating steps of $I_{\mathrm{A}}$ was measured to be $-43 \mathrm{mV}$, substantially more negative than the value measured by Golowasch and Marder (1992) in the LP neuron of the crab Cancer borealis. With these parameters, the model cell behaves like the real cell in the following respects:

(1) The model cell is quiescent with a resting potential of $-53.6 \mathrm{mV}$ without current injection, but fires tonically with sufficient current injection $\left(I_{\text {ext }}\right)$. Increasing current injection evokes tonic activity at increasing frequencies (Fig. 10D $D_{2}$.

(2) The model cell shows a strong dependence of latency to first spike on the magnitude of the previous hyperpolarizing prepulse. Figure $9 A$ shows a plot of voltage traces from a sequence of hyperpolarizing presteps of increasing magnitude followed by a fixed depolarizing step. This can be compared with the response of a real dopamine-responsive PY cell (Fig. 2). The range of voltages for which latency depends upon the magnitude of the hyperpolarizing prestep voltage matches the experimental data.

(3) The model shows appropriate dependence of latency to first spike on the maximal conductance and voltage dependence 
Table 2. Mathematical model of the PY neuron

$$
\begin{aligned}
& C_{m} \dot{v}=-(\underbrace{\bar{g}_{N a} m_{\infty}^{3} h\left(E_{N a}^{\prime}-v\right)}_{I_{N a}}+\underbrace{\left(\bar{g}_{C a 1} a_{C a 1} b_{C a 1}+\bar{g}_{C a 2} a_{C a 2}\right)\left(E_{C a}-v\right)}_{I_{C a}} \\
& +\underbrace{\bar{g}_{K} n^{4}\left(E_{K}-v\right)}_{I_{K(V)}}+\underbrace{\bar{g}_{K(C a)} a_{K(C a)} b_{K(C a)}\left(E_{K}-v\right)}_{I_{K(C a)}} \\
& +\underbrace{\left(\bar{g}_{A f} b_{A f}+\bar{g}_{A s} b_{A s}\right) a_{A}^{3}\left(E_{K}-v\right)}_{I_{A}}+\underbrace{\bar{g}_{l}\left(E_{l}-v\right)}_{I_{l}})+I_{e x t} \\
& I_{N a}:\left\{\begin{array}{l}
m_{\infty}=\left(1+15 e^{\left.-0.0769(v+34) \frac{\left(1-e^{-0.05(v+6)}\right)}{0.11 v+0.66}\right)^{-1}}\right. \\
\dot{h}=k_{h}\left(0.08(1-h) e^{-0.125(v+39)}-\frac{h}{1+e^{-(0.2 v+8)}}\right)
\end{array}\right. \\
& I_{C a}:\left\{\begin{array}{l}
\dot{C}_{a}=-c_{i C a}\left(\bar{g}_{C a 1} a_{C a 1} b_{C a 1}+\bar{g}_{C a 2} a_{C a 2}\right)\left(v-E_{C a}\right)+k_{C a}(0.05-C a) \\
\dot{a}_{C a 1}=50\left(1+e^{-0.143(v+11)}\right)^{-1}-50 a_{C a 1} \\
\dot{a}_{C a 2}=10\left(1+e^{-0.143(v-22)}\right)^{-1}-10 a_{C a 2} \\
\dot{b}_{C a 1}=16\left(1+e^{0.125(v+50)}\right)^{-1}-16 b_{C a 1}
\end{array}\right. \\
& I_{K(V)}:\left\{\dot{n}=\left(180\left(1+e^{-0.0588(v+25)}\right)^{-1}-180 n\right)\left(1+e^{-0.0455(v-10)}\right)^{-1}\right. \\
& I_{K(C a)}:\left\{\begin{array}{l}
\dot{a}_{K(C a)}=k_{K(C a)}\left(\frac{C a}{\left(1+e^{-(0.0435 v+0.026 C a)}\right)\left(1+e^{-(0.2 v+3.2+0.12 C a}\right)(2.5+C a)}-a_{K(C a)}\right) \\
\dot{b}_{K(C a)}=\frac{21}{0.6+C a}-35 b_{K(C a)}
\end{array}\right. \\
& I_{A}:\left\{\begin{array}{l}
\dot{a}_{A}=\frac{140}{\left.1+e^{-0.0667(v-v} A\right)-140 a_{A}} \\
\dot{b}_{A f}=k_{A f}\left(\left(1+e^{0.167(v+31)}\right)^{-1}-b_{A f}\right) \\
\dot{b}_{A s}=k_{A s}\left(\left(1+e^{0.167(v+31)}\right)^{-1}-b_{A s}\right)
\end{array}\right.
\end{aligned}
$$

of the slowly inactivating component of $I_{\mathrm{A}}$. A typical example is shown in Figure 9, which shows the effect of mimicking the actions of dopamine by reducing $\tilde{g}_{\mathrm{A}}$, the maximal conductance of the slowly inactivating component of $I_{\mathrm{A}}$, from 1.2 to $0.7 \mu \mathrm{S} /$ $\mathrm{nF}$, and by shifting the voltage for half-activation, $V_{\mathrm{A}}$, from -43 to $-37 \mathrm{mV}$. The model cell responds like the real dopamineresponsive PY neuron by depolarizing from its resting potential of $-53.6 \mathrm{mV}$ and firing tonic action potentials (not shown). The latency to first spike is reduced at all voltages by the parameter changes mimicking dopamine's actions on real dopamine-responsive PY cells (compare Figs. $3 A, 9 B$ ). Both parameters of $I_{\mathrm{A}}$ contribute significantly to the reduction in latency to first spike. Their independent effects are shown in Figurc 10, $A$ and $B$. Figure $10 A$, shows the latency following a prestep to -80 $\mathrm{mV}$ as a function of $\bar{g}_{\mathrm{As}}$, the maximal conductance of the slowly inactivating component of $I_{\mathrm{A}}$; clearly, the changes evoked by dopamine in this parameter can strongly affect the latency. Figure $10 B$, shows the effect of changes in $V_{A}$, the voltage halfactivation parameter, and demonstrates that even subtle effects on this parameter, such as are observed with dopamine, evoke significant changes in the latency.
(4) When depolarized by current injection to fire tonically following a hyperpolarizing prepulse, the model shows substantial dependence of firing frequency on the parameters of $I_{\mathrm{A}}$ that are modulated by dopamine (though not as much as the real cell). For example, reduction of $\bar{g}_{\mathrm{A} s}$ and $V_{\mathrm{A}}$, mimicking dopamine's actions, reduced the tonic interspikc intcrval during a 1 nA current injection from $89 \mathrm{msec}$ to $68 \mathrm{msec}$. In Figure 9, $B$ and $D$ show that the initial interspike interval following a hyperpolarizing prestep is particularly sensitive to reduction of $I_{\mathrm{A}}$. Under "control" conditions, the model shows only slight dependence of this interval on the amplitude of the hyperpolarizing prestep, but reduction of $I_{\mathrm{A}}$ mimicking the parameters altered by dopamine reveals a somewhat stronger voltage dependence (Fig. 9D). In Figure 10, $A_{2}$ and $B_{2}$ show the dependence of the first interspike interval on $\bar{g}_{A s}$ and $V_{\mathrm{A}}$. The interspike interval is a monotonic function of each of these parameters, consistent with the effects of dopamine on the same parameters in the real dopamine-responsive PY neuron.

We have explored the effect of several other parameters on latency and first interspike interval in the PY cell model. Reducing $\bar{g}_{\mathrm{K}(i)}$, the maximal conductance of the delayed rectifier 


\begin{tabular}{|c|c|c|c|}
\hline Parameter & Value & Meaning & Units \\
\hline $\bar{g}_{\mathrm{A} /}$ & 0.7 & Fast $A$ current conductance & $\mu \mathrm{S}$ \\
\hline $\bar{g}_{\mathrm{As}}$ & 1.2 & Slow A current conductance & $\mu \mathrm{S}$ \\
\hline $\bar{g}_{\mathrm{K}(\mathrm{Ca})}$ & 5.9 & $\mathrm{~K}(\mathrm{Ca})$ current conductance & $\mu \mathrm{S}$ \\
\hline$g_{K}$ & 0.42 & $\mathrm{~K}$ current conductance & $\mu \mathrm{S}$ \\
\hline $\bar{g}_{\text {Cal }}$ & 0.21 & Inactivating $\mathrm{Ca}$ current conductance & $\mu \mathrm{S}$ \\
\hline $\bar{g}_{\mathrm{Ca} 2}$ & 0.047 & Noninactivating $\mathrm{Ca}$ current conductance & $\mu \mathrm{S}$ \\
\hline$g_{l}$ & 0.1 & Leak current conductance & $\mu \mathrm{S}$ \\
\hline$\ddot{g}_{\mathrm{Na}}$ & 2300 & Na current conductance & $\mu \mathrm{S}$ \\
\hline$E_{\mathrm{K}}$ & -86 & Potassium reversal potential & $\mathrm{mV}$ \\
\hline$E_{l}$ & -50 & Leak reversal potential & $\mathrm{mV}$ \\
\hline$E_{\mathrm{Ca}}$ & 140 & Ca reversal potential & $\mathrm{mV}$ \\
\hline$E_{\mathrm{Na}}$ & 50 & Sodium reversal potential & $\mathrm{mV}$ \\
\hline$v_{\mathrm{A}}$ & -43 & A current half-activation & $\mathrm{mV}$ \\
\hline$k_{\mathrm{K}(\mathrm{Ca})}$ & 600 & $1 /(\mathrm{K}(\mathrm{Ca})$ activation time constant $)$ & $\mathrm{msec}^{-1}$ \\
\hline$c_{\mathrm{iCa}}$ & 300 & $1 /(\mathrm{Ca}$ concentration time constant $)$ & $\mathrm{msec}^{-1}$ \\
\hline$k_{\mathrm{Ca}}$ & 360 & $1 /($ Ca decay time constant $)$ & $\mathrm{msec}^{-1}$ \\
\hline$k_{\mathrm{A} f}$ & 45 & $1 /($ fast $\mathrm{A}$ inactivation time constant $)$ & $\mathrm{msec}^{-1}$ \\
\hline$k_{\mathrm{As}}$ & 10 & $1 /($ slow $\mathrm{A}$ inactivation time constant $)$ & $\mathrm{msec}^{-1}$ \\
\hline$k_{h}$ & 500 & $1 /(\mathrm{Na}$ inactivation time constant $)$ & $\mathrm{msec}^{-1}$ \\
\hline$C_{m}$ & 0.0017 & Membrane capacitance & $\mathrm{nF}$ \\
\hline
\end{tabular}

current, $I_{\mathrm{K}(i)}$, has little effect on latency (Fig. $10 C_{l}$ ), but causes a pronounced increase in the firing frequency of the cell. This can be seen by the very strong dependence of first interspike interval on $\bar{g}_{\mathrm{K}(\eta)}$ (Fig. 10C ). Increasing the external current injection, $I_{\mathrm{ext}}$, both reduces latency (Fig. 10D ) and increases firing frequency, (Fig. 10D ) consistent with our observations in real dopamine-responsive PY neurons. Combined changes in both latency and first interspike interval showed greatest dependence on alterations in the parameters of $I_{\mathrm{A}}\left(\bar{g}_{\mathrm{A} s}\right.$ and $\left.V_{\mathrm{A}}\right)$. Thus, the observed changes in postinhibitory rebound seen with dopamine are qualitatively reproduced by simulating dopamine's effects on $I_{\mathrm{A}}$ in our model.

Our current model does not perfectly reproduce the responses of the experimental PY neuron during current injection. Following a hyperpolarizing prestep, the model rapidly approaches its final tonic spiking frequency during the subsequent depolarizing current step. Thus, there is only a small dependence of interspike interval on the hyperpolarizing prestep amplitude, unlike the real PY neuron (Fig. 9D, control curve). After changing parameters to mimic the effects of dopamine, a more marked voltage dependence in first interspike interval is obtained (Fig. $9 D$, dopamine simulation curve), but there is little dependence on hyperpolarizing prestep amplitude for spike frequency after the first interspike interval (Fig. 9B). Presumably, hyperpolarization activates an additional slow adaptive process in the real cell that only slowly relaxes upon depolarization, constraining the cell to fire at lower frequencies for prolonged periods of time; we do not know what this process is, and as a result it is not present in the model.

\section{Discussion}

Two major mechanisms can alter the timing of a neuron's activity in a rhythmic motor pattern: changes in synaptic input and changes in the neuron's intrinsic response properties (Get- ting, 1989; Harris-Warrick and Marder, 1991; Harris-Warrick et al., 1992c). Most research to date on phase shifts has focused on synaptic mechanisms: if a neuron receives more excitatory or less inhibitory synaptic input, this could cause a phase advance of its activity during the cycle (Cohen and Harris-Warrick, 1984; Eisen and Marder, 1984; Sharp et al., 1992). Changes in synaptic input can result from a variety of causes, including excitation or inhibition of presynaptic neurons, modulation of transmitter release, and modulation of postsynaptic sensitivity to the transmitter (Kaczmarek and Levitan, 1987). Eisen and Marder (1984) showed that part of the dopamine-induced PY phase advance in the pyloric rhythm results from loss of synaptic inhibition by the pacemaker PD neurons. Dopamine directly inhibits the PD neurons (Eisen and Marder, 1984; Flamm and Harris-Warrick, 1986b), and eliminates their chemical synaptic transmission (Johnson and Harris-Warrick, 1990). With this loss of PD inhibition, the PY cells recover to fire at an earlier phase.

A second mechanism for phase shifts is to modulate the postsynaptic cell's intrinsic response to synaptic input. This can also occur in a variety of ways. For example, simple input resistance changes can alter the degree of shunting of synaptic current flow within the cell. More complex forms of conductance modulation can affect how the cell interprets the synaptic input, including modulation of bistability, plateau potential capability, rhythmic bursting and postinhibitory rebound (Nagy and Dickinson, 1983; Nagy et al., 1988; Heinzel and Selverston, 1988). In this article, we have shown how modulation of a specific voltage-dependent current, $I_{\mathrm{A}}$, can modify the rate of postinhibitory rebound in some PY cells and shift their firing phase in the rhythmic pyloric motor pattern. Four results support this conclusion.

(1) Dopamine evokes an increase in the input resistance of responsive PY cells. This suggests that dopamine acts predominantly by closing ion channels that are open at rest. The transient $\mathrm{K}^{+}$current appears to be partially activated at the normal 


\section{A Control}
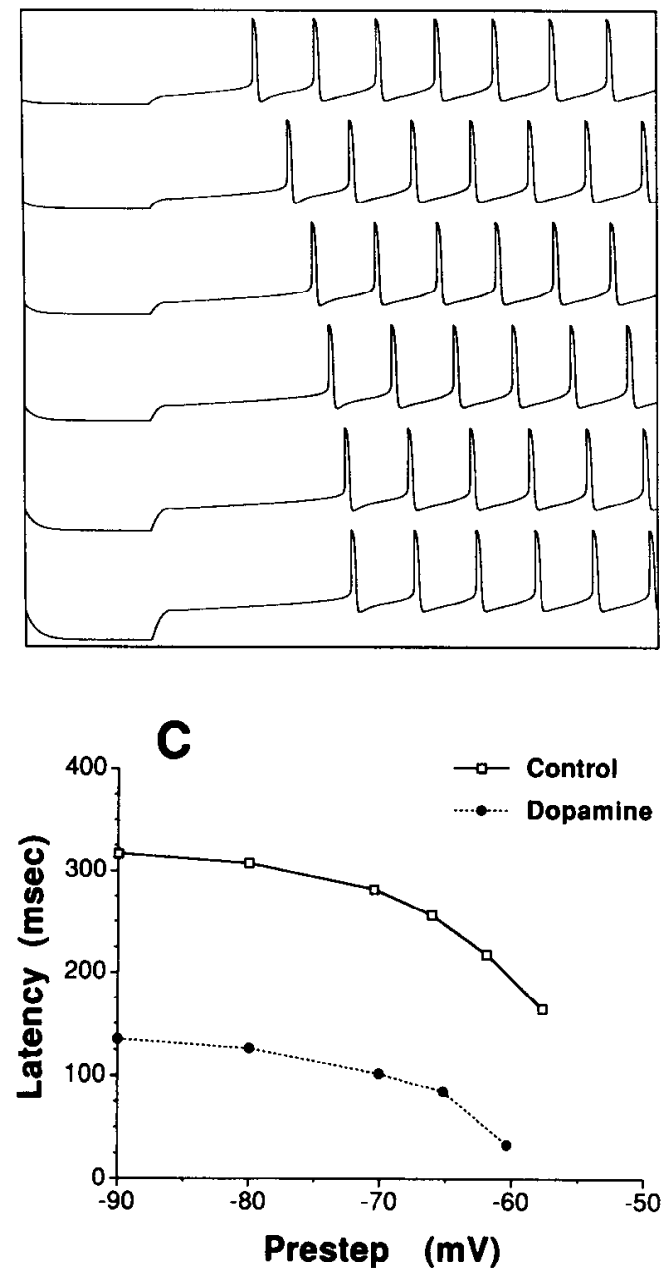

B Dopamine
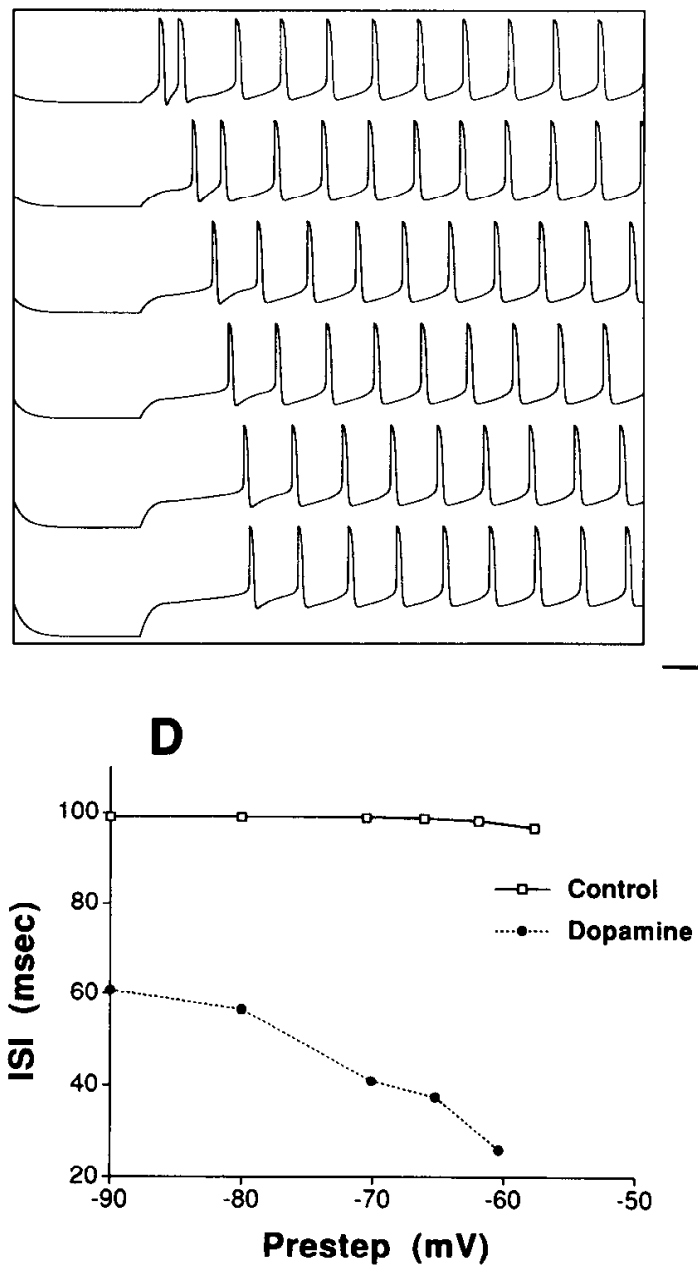

Figure 9. Mathematical model of the PY neuron shows appropriate changes in activity when the effects of dopamine are mimicked. $A$ and $B$, Traces of voltage versus time for control and simulated dopamine conditions. Cell is held at $-55 \mathrm{mV}$, and 200 msec hyperpolarizing current pulses of increasing amplitude are injected, followed by a $1 \mathrm{nA}$ depolarizing pulse. Voltage marker, $100 \mathrm{mV}$; time marker, $100 \mathrm{msec}$. $C$, Dependence of delay to first spike on the amplitude of the hyperpolarizing prestep under control and simulated dopamine conditions. $D$, Dependence of the first interspike interval $(I S I)$ on amplitude of the hyperpolarizing prestep under control and simulated dopamine conditions. Control parameters $(A$, $C)$ are those given in Table 2. Simulated dopamine parameters $(B, D)$ are identical with two exceptions: $\bar{g}_{\mathrm{A}}$, the maximal conductance of the slowly inactivating component of $I_{\mathrm{A}}$, is reduced from 1.2 to $0.7 \mu \mathrm{S} / \mathrm{nF}$ and $V_{\mathrm{A}}$, the voltage for half-maximal activation of the individual gating events for $I_{\mathrm{A}}$, is altered from -43 to $-37 \mathrm{mV}$.

resting potential of the PY cells, since selective blockade with 4-AP causes the neurons to depolarize and spike tonically (Ticrney and Harris-Warrick, 1992). In addition, our curve fits for the activation and inactivation of $I_{\mathrm{A}}$ overlap in the region between -60 and $-30 \mathrm{mV}$ (Fig. $5 D$ ), allowing a small steady state $I_{\mathrm{A}}$ to contribute to the active membrane conductance at the normal resting potential $(-55 \mathrm{mV})$. An alternative explanation of our data is that in addition to reducing $I_{\mathrm{A}}$, dopamine reduces a 4-AP-sensitive leak current that is different from $I_{\mathrm{A}}$ and is active at the $P Y$ resting potential; however, we have no evidence for this hypothesis. Johnson et al. (1993a) did not report a significant increase in input resistance in PY cells during dopamine superfusion, although a trend in this direction was observed. This may reflect their inclusion of both dopamine-responsive and dopamine-nonresponsive PY neurons in their analysis.

(2) In voltage clamp, dopamine reduces $I_{\mathrm{A}}$, specifically by decreasing $\bar{g}_{\mathrm{As}}$, the amplitude of the more slowly inactivating component of the current, and shifting $V_{A}$, its voltage for halfactivation, toward more depolarized voltages. In addition, there was a trend for dopamine to shift the half-inactivation voltage to the right, though this effect was not statistically significant. Dopamine has little effect on the rapidly inactivating component of $I_{\mathrm{A}}$. There are two interpretations of these results. First, the PY neurons may express multiple channels with transient $I_{\mathrm{A}^{-}}$ like characteristics but different inactivation rates, similar to the shaker and shal genes and their alternatively spliced products in Drosophila (Schwarz et al., 1988; Butler et al., 1989; Wei ct al., 1990). Dopamine may selectively inactivate one channel subtype, with little effect on others. Second, dopamine may modulate a single A channel with complex, multicomponent inactivation kinetics, such as are seen with Drosophila shaker cRNA expressed in Xenopus oocytes (Timpe et al., 1988). These interpretations cannot be tested until the expression profile of 

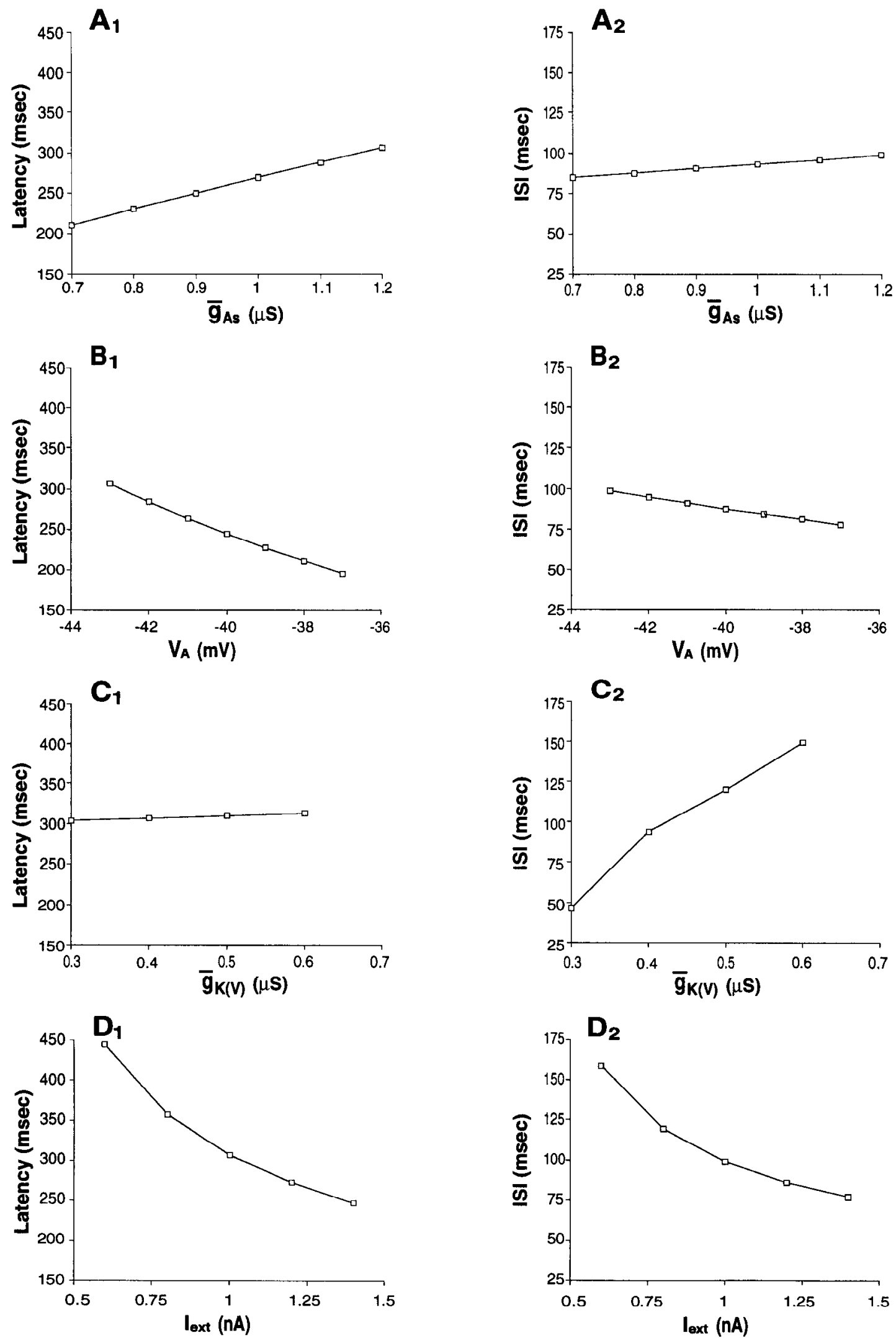

Figure 10. Model PY cell responses to alterations in parameters. The left column shows the dependence of latency to first spike, while the right column shows the dependence of the first interspike interval $(I S I)$, on the parameters $g_{\mathrm{As}}(A), V_{\mathrm{A}}(B), g_{\mathrm{K}(\nu)}(C)$ and $I_{\text {exl }}(D)$. For all figures, the parameters are initially set to values listed in Table 2 , and the indicated parameter is then sequentially changed. The cell is held at $-55 \mathrm{mV}$, given a $200 \mathrm{msec}$ prestep to $-80 \mathrm{mV}$, and then given a $1 \mathrm{nA}$ depolarizing current step to evoke tonic spiking; an example is given in Figure $9, A$ and $B$. 
different potassium channel genes in the PY cells is known (Baro et al., 1993).

(3) 4-Aminopyridine, which selectively blocks $I_{\mathrm{A}}$ in the crustacean stomatogastric ganglion (Graubard and Hartline, 1991; Tierney and Harris-Warrick, 1992), mimics and occludes the effects of dopamine in synaptically isolated PY neurons. Both dopamine and 4-AP cause responsive neurons to depolarize and fire tonically, and reduce the latency to first spike and first interspike interval. In the presence of sufficient 4-AP to completely eliminate $I_{\mathrm{A}}$, dopamine has no significant effect on the responsive PY neuron. In the intact pyloric network, 4-AP enhances activity of most pyloric neurons, including the PY cells, and evokes a significant phase advance in PY activity in the cycle (Tierney and Harris-Warrick, 1992). Pharmacological blockers of other hyperpolarization-activated currents do not affect the PY cell's response to dopamine. For example, low concentrations of extracellular cesium, which block both $I_{h}$ and the inwardly rectifying potassium current $\left.I_{\mathrm{K}(\mathrm{IR}}\right)$ in many cell types (McCormick and Pape, 1990; Golowasch et al., 1992; Golowasch and Marder, 1992; Hille, 1992; Kiehn and Harris-Warrick, 1992a,b), had no significant effect on dopamine modulation of the PY cells. This suggests that $I_{h}$ and $I_{\mathrm{K}(\mathrm{IR})}$, which are not detectable by voltage clamp in most PY cells, are not significant targets of dopamine modulation in these cells. However, they are important in other neurons. $I_{h}$ plays a role in postinhibitory rebound and phasing among leech heart interneurons (Angstadt and Calabrese, 1989). Modulation of the voltage dependence of $I_{h}$ (along with a reduction in $I_{\mathrm{A}}$ ) helps to determine the dopamine-evoked phase advance of another neuron in the pyloric network, the lateral pyloric (LP) cell (Harris-Warrick et al., 1992d; unpublished observations). The T-type low threshold calcium current is another subthreshold current that affects postinhibitory rebound. Differential expression of this calcium current evokes different rates of postinhibitory rebound in two types of sensory neurons in the lamprey (Christenson et al., 1993).

(4) A mathematical model of the dopamine-responsive PY neuron has been adapted from the LP model of Buchholtz et al. (1992). When dopamine's effects on $\bar{g}_{S}$ and $V_{\mathrm{A}}$ are simulated, the model shows appropriate changes in the PY rebound time and interspike interval. The model, however, does not show a strong dependence of interspike interval on the amplitude of the hyperpolarizing prepulse that is seen in the real PY neuron under control conditions. In addition, the model does not reproduce well the slow recovery of the frequency of tonic spiking following a hyperpolarizing prepulse: the model cell reaches its asymptotic state within one or two spikes following rebound. This suggests that there are hyperpolarization-activated slow currents that are not represented in our model. While the model is not correct in every detail, it demonstrates that changes in $I_{\text {A }}$ are sufficient to explain the effects of dopamine on postinhibitory rebound in the PY cell.

\section{Relationship between rebound rate and interspike interval}

Dopamine simultaneously increases the rebound rate following a hyperpolarizing prestep and increases the tonic spike frequency during depolarization of a subset of the PY neurons. We hypothesize that a reduction of $I_{\mathrm{A}}$ is responsible for both of these effects. $I_{\mathrm{A}}$ plays an important role in determining the tonic spike frequency in a number of neurons (Connor and Stevens, 1971; Segal et al., 1984; Hille, 1992), including the pyloric neurons in Panulirus interruptus (Tierney and Harris-Warrick, 1992). We have previously shown that 4-AP block of $I_{\mathrm{A}}$ evokes phase advances of responsive PY and other cells in the pyloric rhythm (Tierney and Harris-Warrick, 1992); $I_{\mathrm{A}}$ also helps determine phasing in the swim pattern generator in Tritonia (Getting, 1983).

To understand better the factors that play a role in determining the relationship between rebound time and interspike interval, we have analyzed the dependence of these variables on several important parameters in our mathematical model of the PY cell. Bifurcation surfaces separate the regions of the model's multidimensional parameter space in which there is a quiescent steady state or tonic firing. Crossing these bifurcation surfaces with changes in a parameter (such as the maximal conductance of an ionic current) alters the state of the cell. The "scenarios" of cellular responses associated with these changes depend upon which parameters are altered, and thus where in the parameter space one crosses a bifurcation surface. Some (but not all) of the scenarios result in a strong correlation of latency to first spike following a hyperpolarizing prestep and interspike interval during tonic firing. One of these, the "saddle-node in a cycle" scenario, appears in the model cell and mimics the effects of dopamine, so we describe it here.

The latency to first spike is determined by the rate of depolarization following the hyperpolarizing prestep. With increasing latencies, the cell passes through a phase in which the rate of depolarization becomes smaller and smaller. As this rate falls to zero, the cell crosses the bifurcation surface to achieve a quiescent state. Similarly, approaching the bifurcation surface from the opposite side, when the tonically firing cell slows and stops firing, a smooth decrease in the frequency of firing is associated with a slower rate of depolarization between action potentials. In the saddle-node scenario, the mechanisms responsible for the slow rebound of a hypcrpolarized cell and for the slow depolarization of a tonically firing cell are the same. At the bifurcation surface, a pair of equilibrium steady states are created that leave the cell in a state that is potentially excitable, but has no limit cycle and therefore does not fire action potentials. One of the equilibrium points is the stable quiescent state. The second is a saddle point that is not stable. Perturbations from this state either lead monotonically toward quiescence or to excitable states that fire a single action potential before reaching quiescence. Variation of any parameter in the model that carries one across the bifurcation surface from spiking to nonspiking regions of parameter space will produce the same qualitative effects of a simultaneous smooth slowing of the tonic spike frequency and smooth increase of latency to first spike following a hyperpolarizing prepulse, which were also seen with the biological experiments (Figs. 3,4). When we modeled the effects of dopamine in the responsive PY neuron by reducing the maximal conductance and shifting the voltage dependence of $I_{\mathrm{A}}$, the model showed simultaneous alterations in latency and interspike interval (Fig. 9). We interpret this correlation between spiking frequency and rebound time as a natural corollary of the fact that the cell is operating in a region of its parameter space that lies close to a "saddle-node in a cycle" bifurcation surface. In contrast, modeling a reduction in the maximal conductance of $I_{\mathrm{K}(\nu)}$ had a strong effect on the interspike interval (Fig. $10 C_{2}$ ), but only weakly modified the latency to first spike following a hyperpolarizing prepulse (Fig. 10C $C_{l}$ ). This occurs because $I_{\mathrm{K}(V)}$ is not significantly activated at the subthreshold voltages traversed following the hyperpolarizing prestep but is significantly activated by the depolarization accompanying the action potential.

Modulation of motor patterns allows an anatomically defined 
neural nctwork to generate a variety of related behaviors. Our study has focused on a single parameter of this modulation, phase advances in responsive $P Y$ neurons evoked by dopamine in the pyloric motor pattern. Dopamine excites and phase-advances these neurons by reducing the transient $\mathrm{K}^{+}$current, $I_{\mathrm{A}}$. Other intrinsic cellular mechanisms for phase changes exist and are likely to be important in both other neurons in the pyloric network (Harris-Warrick et al., 1992d) and other systems.

\section{References}

Angstadt JD, Calabrese RL (1989) A hyperpolarization-activated inward current in heart interneurons of the medicinal leech. J Neurosci 9:2846-2857.

Back A, Guckenheimer J, Myers M, Wicklin F, Worfolk P (1992) DsTool: computer-assisted exploration of dynamical systems. Notices Am Math Soc 39:303-309.

Baro DJ, Cole C, Tapia M, Zarrin A, Chen A, Podleski TR, HarrisWarrick RM (1993) Expression of Shaker family K+ channel mRNA in the spiny lobster, Panulirus interruptus. Soc Neurosci Abstr 18:77.

Bidaut M (1980) Pharmacological dissection of pyloric network of the lobster stomatogastric ganglion using picrotoxin. J Neurophysiol 44: 1089-1101.

Buchholtz F, Golowasch J, Epstein IR, Marder E (1992) Mathematical model of an identified stomatogastric ganglion neuron. J Neurophysiol 67:332-340.

Butler A, Wei A, Baker K, Salkoff L (1989) A family of putative potassium channel genes in Drosophila. Science 243:943-947.

Christenson J, Hill RH, Bongianni F, Grillner S (1993) Presence of low voltage activated calcium channels distinguishes touch from pressure sensory neurons in the lamprey spinal cord. Brain Res 608:5866.

Cohen AH, Harris-Warrick RM (1984) Strychnine eliminates alternating motor output during fictive locomotion in the lamprey. Brain Res 293:164-167.

Connor JA, Stevens CF (1971) Prediction of repetitive firing behavior from voltage clamp behavior on an isolated neurone soma. J Physiol (Lond) 213:31-53.

Eisen JS, Marder E (1982) Mechanisms underlying pattern generation in lobster stomatogastric ganglion as determined by selective inactivation of identified neurons. III. Synaptic connections of electrically coupled pyloric neurons. J Neurophysiol 48:1392-1415.

Eisen JS, Marder E (1984) A mechanism for the production of phase shifts in a pattern generator. J Neurophysiol 51:1375-1393.

Elson RC, Selverston AI (1992) Mechanisms of gastric rhythm generation in the isolated stomatogastric ganglion of spiny lobsters: bursting pacemaker potentials, synaptic interactions and muscarinic modulation. J Neurophysiol 68:890-907.

Flamm RE, Harris-Warrick RM (1986a) Aminergic modulation in the lobster stomatogastric ganglion. I. Effects on the motor pattern and activity of neurons within the pyloric circuit. $J$ Neurophysiol 55 : 847-865.

Flamm RE, Harris-Warrick RM (1986b) Aminergic modulation in the lobster stomatogastric ganglion. II. Target neurons of dopamine, octopamine and serotonin within the pyloric circuit. J Neurophysiol 55:866-881.

Getting PA (1983) Mechanisms of pattern generation underlying swimming in Tritonia. III. Intrinsic and synaptic mechanisms for delayed excitation. J Neurophysiol 49:1036-1050.

Getting PA (1989) Emerging principles governing the operation of neural networks. Annu Rev Neurosci 12:185-204.

Golowasch JP (1991) Characterization of a stomatogastric ganglion neuron. $\Lambda$ biophysical and a mathematical description. PhD thesis, Brandeis University.

Golowasch J, Marder E (1992) Ionic currents of the lateral pyloric neuron of the stomatogastric ganglion of the crab. J Neurophysiol 67: 318-331.

Golowasch J, Buchholtz F, Epstein IR, Marder E (1992) The contribution of individual ionic currents to the activity of a model stomatogastric ganglion neuron. J Neurophysiol 67:341-349.

Graubard K, Hartline DK (1991) Voltage clamp analysis of intact stomatogastric neurons. Brain Res 557:241-254.

Grillner S (1981) Control of locomotion in bipeds, tetrapods and fish.
In: Handbook of physiology, Sec 1, The nervous system (Brooks VB, ed), pp 1179-1236. Bethesda, MD: American Physiological Society.

Harris-Warrick RM (1989) Forskolin reduces a transient potassium current in lobstcr ncurons by a cAMP-independent mechanism. Brain Res 489:59-66.

Harris-Warrick RM, Flamm RE (1987) Multiple mechanisms of bursting in a conditional bursting neuron. $J$ Neurosci 7:2113-2128.

Harris-Warrick RM, Marder E (1991) Modulation of neural networks for behavior. Annu Rev Neurosci 14:39-57.

Harris-Warrick RM, Flamm RE, Johnson BR, Katz PS, Kiehn O, Zhang B (1992a) Amine modulation in the crustacean stomatogastric ganglion. In: Proceedings of Neurotox '91 (Duce IR, ed), pp 305-321. Cambridge: Elsevier.

Harris-Warrick RM, Marder E, Selverston AI, Moulins M, eds (1992b) Dynamic biological networks. The stomatogastric nervous system. Cambridge, MA: MIT Press.

Harris-Warrick RM, Nagy F, Nusbaum MP (1992c) Neuromodulation of stomatogastric networks by identified neurons and transmitters. In: Dynamic biological networks. The stomatogastric nervous system (Harris-Warrick RM, Marder E, Selverston AI, Moulins M, eds), pp 87-138. Cambridge, MA: MIT Press.

Harris-Warrick RM, Tierney AJ, Coniglio L (1992d) Mechanisms for dopamine-induced phase shifts in the pyloric motor pattern in the lobster stomatogastric ganglion. Soc Neurosci Abstr 18:1055.

Hartline DK (1979) Pattern generation in the lobster (Panulirus) stomatogastric ganglion. II. Pyloric network simulation. Biol Cybern 33: 223-236.

Hartline DK, Graubard K (1992) Cellular and synaptic properties in the crustacean stomatogastric nervous system. In: Dynamic biological networks. The stomatogastric nervous system (Harris-Warrick RM, Marder E, Selverston AI, Moulins M, eds), pp 31-86. Cambridge, MA: MIT Press.

Heinzel HG, Selverston AI (1988) Gastric mill activity in the lobster III. Effects of proctolin on the isolated central pattern generator. J Neurophysiol 59:566-585.

Hartline DK, Gassie DV, Sirchia CD (1987) PY cell types in the stomatogastric ganglion of Panulirus. In: The crustacean stomatogastric system (Selverston AI, Moulins M, eds), pp 75-77. Berlin: Springer.

Hartline DK, Russell DF, Raper JA, Graubard K (1988) Special cellular and synaptic mechanisms in motor pattern generation. Comp Biochem Physiol 91:115-131.

Hartline DK, Gassie DV, Jones BR (1993) Effects of soma isolation on outward currents measured under voltage clamp in spiny lobster stomatogastric motor neurons. J Neurophysiol 69:2056-2071.

Hille B (1992) Ionic channels of excitable membranes. Sunderland, MA: Sinauer

Johnson BR, Harris-Warrick RM (1990) Aminergic modulation of graded synaptic transmission in the lobster stomatogastric ganglion. J Neurosci 10:2066-2076.

Johnson BR, Hooper SL (1992) Overview of the stomatogastric nervous system. In: Dynamic biological networks. The stomatogastric nervous system (Harris-Warrick RM, Marder E, Selverston AI, Moulins M, eds), pp 1-30. Cambridge, MA: MIT Press.

Johnson BR, Peck JH, Harris-Warrick RM (1993a) Amine modulation of electrical coupling in the pyloric network of the lobster stomatogastric ganglion. J Comp Physiol [A] 172:715-732.

Johnson BR, Peck JH, Harris-Warrick RM (1993b) Dopamine induces sign reversal at mixed chemical-electrical synapses. Brain Res 625:159-164.

Kaczmarek LK, Levitan IB (1987) Neuromodulation. New York: Oxford UP.

Kiehn O, Harris-Warrick RM (1992a) Serotonergic stretch receptors induce plateau properties in a crustacean motor neuron by a dualconductance mechanism. J Neurophysiol 68:485-495.

Kiehn O, Harris-Warrick RM (1992b) 5-HT modulation of hyperpolarization-activated inward current and calcium-dependent outward current in a crustacean motor neuron. J Neurophysiol 68:496508 .

McCormick DA, Pape H-E (1990) Properties of a hyperpolarizationactivated cation current and its role in rhythmic oscillation in thalamic relay neurons. J Physiol (Lond) 431:291-318.

Miller JP (1987) Pyloric mechanisms. In: The crustacean stomatogastric system (Selverston AI, Moulins M, eds), pp 109-136. Berlin: Springer. 
Miller JP, Selverston AI (1979) Rapid killing of single neurons by irradiation of intracellularly injected dye. Science 206:702-704.

Mulloney B, Selverston AI (1974) Organization of the stomatogastric ganglion in the spiny lobster. I. Neurons driving the lateral teeth. J Comp Physiol 91:1-32.

Nagy F, Dickinson PS (1983) Control of a central pattern generator by an identified modulatory interneurone in crustacea. I. Modulation of the pyloric motor output. J Exp Biol 105:33-58.

Nagy F, Dickinson PS, Moulins M (1988) Control by an identified neuron of the sequential expression of plateau properties of, and synaptic inputs to, a neuron in a central pattern generator. J Neurosci 8:2875-2886.

Nusbaum MP, Weimann JM, Golowasch J, Marder E (1992) Presynaptic control of modulatory fibers by their neural network targets. J Neurosci 12:2706-2714.

Pearson KG (1993) Common principles of motor control in vertebrates and invertebrates. Annu Rev Neurosci 16:265-297.

Russell DF (1979) CNS control of pattern generation in the lobster stomatogastric ganglion. Brain Res 177:598-602.

Schwarz TL, Tempel BL, Papazian DM, Jan YN, Jan LY (1988) Multiple potassium-channel components are produced by alternative splicing at the Shaker locus in Drosophila. Nature 331:137-142.
Segal M, Rogawski MA, Barker JL (1984) A transient potassium conductance regulates excitability of cultured hippocampal and spinal neurons. J Neurosci 4:604-609.

Selverston AI, Moulins M (1985) Oscillatory neural networks. Annu Rev Physiol 47:29-48.

Selverston AI, Moulins M, eds (1987) The crustacean stomatogastric system. Berlin: Springer.

Sclvcrston AI, Russell DF, Miller JP, King DG (1976) The stomatogastric nervous system: structure and function of a small neural network. Prog Neurobiol 7:215-290.

Sharp AA, Abbott LF, Marder E (1992) Artificial electrical synapses in oscillatory neurons. J Neurophysiol 67:1691-1694.

Tierney AJ, Harris-Warrick RM (1992) Physiological role of the transient potassium current in the pyloric circuit of the lobster stomatogastric ganglion. J Neurophysiol 67:599-609.

Timpe LC, Schwarz TL, Tempel BL, Papazian DM, Jan YN, Jan LY (1988) Expression of functional potassium channels from Shaker cDNA in Xenopus oocytes. Nature 331:137-142.

Wei A, Covarrubias M, Butler A, Baker K, Pak M, Salkoff L (1990) $\mathrm{K}^{+}$current diversity is produced by an extended gene family conserved in Drosophila and mouse. Science 248:599-603. 